Published in final edited form as:

Am J Obstet Gynecol. 2018 July ; 219(1): 10-25. doi:10.1016/j.ajog.2018.03.028.

\title{
Vaginal progesterone is as effective as cervical cerclage to prevent preterm birth in women with a singleton gestation, previous spontaneous preterm birth, and a short cervix: updated indirect comparison meta-analysis
}

\author{
Dr Agustin Conde-Agudelo, MD, MPH, PhD, \\ Perinatology Research Branch, Division of Obstetrics and Maternal-Fetal Medicine, Division of \\ Intramural Research, Eunice Kennedy Shriver National Institute of Child Health and Human \\ Development, National Institutes of Health, Department of Health and Human Services, \\ Bethesda, MD, and Detroit, MI, Department of Obstetrics and Gynecology, Wayne State \\ University School of Medicine, Detroit, MI
}

\section{Dr Roberto Romero, MD, DMedSci,}

Perinatology Research Branch, Division of Obstetrics and Maternal-Fetal Medicine, Division of Intramural Research, Eunice Kennedy Shriver National Institute of Child Health and Human Development, National Institutes of Health, Department of Health and Human Services, Bethesda, MD, and Detroit, MI, Department of Obstetrics and Gynecology, University of Michigan, Ann Arbor, MI (Dr Romero); Department of Epidemiology and Biostatistics, Michigan State University, East Lansing, MI, Center for Molecular Medicine and Genetics, Wayne State University, Detroit, MI

\section{Dr Eduardo Da Fonseca, MD,}

Departamento de Obstetrícia e Ginecologia, Hospital do Servidor Publico Estadual "Francisco Morato de Oliveira" and School of Medicine, University of São Paulo, São Paulo, Brazil

\section{Dr John M. O’Brien, MD,}

Department of Obstetrics and Gynecology, University of Kentucky, Lexington, KY

\section{Dr Elcin Cetingoz, MD,}

Department of Obstetrics and Gynecology, Turkish Red Crescent Altintepe Medical Center, Maltepe, Istanbul, Turkey

Dr George W. Creasy, MD, Center for Biomedical Research, Population Council, New York, NY

Dr Sonia S. Hassan, MD,

\footnotetext{
Corresponding author: Roberto Romero, MD, DMedSci. prbchiefstaff@med.wayne.edu.

Dr O'Brien was involved in studies of progesterone gel treatment for preterm birth prevention sponsored by a maker of progesterone gel. He served on advisory boards and as a consultant for Watson Pharmaceuticals, a company with a financial interest in marketing vaginal progesterone gel for preterm birth prevention; he and others are listed in a patent on the use of progesterone compounds to prevent preterm birth (US patent 7884093: progesterone for the treatment and prevention of spontaneous preterm birth). He has received no royalty payments. Dr Creasy was an employee of Columbia Laboratories, Inc when the previous indirect comparison meta-analysis was conducted in 2012. The other authors report no conflict of interest.
} 
Perinatology Research Branch, Division of Obstetrics and Maternal-Fetal Medicine, Division of Intramural Research, Eunice Kennedy Shriver National Institute of Child Health and Human Development, National Institutes of Health, Department of Health and Human Services, Bethesda, MD, and Detroit, MI, Department of Obstetrics and Gynecology, Wayne State University School of Medicine, Detroit, MI

\section{Dr Offer Erez, MD,}

Perinatology Research Branch, Division of Obstetrics and Maternal-Fetal Medicine, Division of Intramural Research, Eunice Kennedy Shriver National Institute of Child Health and Human Development, National Institutes of Health, Department of Health and Human Services, Bethesda, MD, and Detroit, MI, Department of Obstetrics and Gynecology, Wayne State University School of Medicine, Detroit, MI, Department of Obstetrics and Gynecology, Soroka University Medical Center, School of Medicine, Faculty of Health Sciences. Ben-Gurion University of the Negev, Beersheba, Israel

Dr Percy Pacora, MD, and Perinatology Research Branch, Division of Obstetrics and Maternal-Fetal Medicine, Division of Intramural Research, Eunice Kennedy Shriver National Institute of Child Health and Human Development, National Institutes of Health, Department of Health and Human Services, Bethesda, MD, and Detroit, MI, Department of Obstetrics and Gynecology, Wayne State University School of Medicine, Detroit, MI

\section{Dr Kypros H. Nicolaides, MD}

Harris Birthright Research Center for Fetal Medicine, King's College Hospital, London, United Kingdom

\section{Abstract}

BACKGROUND: An indirect comparison meta-analysis published in 2013 reported that both vaginal progesterone and cerclage are equally efficacious for preventing preterm birth and adverse perinatal outcomes in women with a singleton gestation, previous spontaneous preterm birth, and a sonographic short cervix. The efficacy of vaginal progesterone has been challenged after publication of the OPPTIMUM study. However, this has been resolved by an individual patientdata meta-analysis.

OBJECTIVE: To compare the efficacy of vaginal progesterone and cerclage in preventing preterm birth and adverse perinatal outcomes in women with a singleton gestation, previous spontaneous preterm birth, and a midtrimester sonographic short cervix.

DATA SOURCES: MEDLINE, EMBASE, LILACS, and CINAHL (from their inception to March 2018); Cochrane databases, bibliographies, and conference proceedings.

STUDY ELIGIBILITY CRITERIA: Randomized controlled trials comparing vaginal progesterone to placebo/no treatment or cerclage to no cerclage in women with a singleton gestation, previous spontaneous preterm birth, and a sonographic cervical length $<25 \mathrm{~mm}$.

STUDY APPRAISAL AND SYNTHESIS METHODS: Updated systematic review and adjusted indirect comparison meta-analysis of vaginal progesterone vs cerclage using placebo/no cerclage as the common comparator. The primary outcomes were preterm birth $<35$ weeks of 
gestation and perinatal mortality. Pooled relative risks (RRs) with 95\% confidence intervals were calculated.

RESULTS: Five trials comparing vaginal progesterone vs placebo (265 women) and 5 comparing cerclage vs no cerclage (504 women) were included. Vaginal progesterone, compared to placebo, significantly reduced the risk of preterm birth $<35$ and $<32$ weeks of gestation, composite perinatal morbidity/mortality, neonatal sepsis, composite neonatal morbidity, and admission to the neonatal intensive care unit (RRs from 0.29 to 0.68 ). Cerclage, compared to no cerclage, significantly decreased the risk of preterm birth $<37,<35,<32$, and $<28$ weeks of gestation, composite perinatal morbidity/mortality, and birthweight $<1500 \mathrm{~g}$ (RRs from 0.64 to 0.70 ). Adjusted indirect comparison meta-analyses did not show statistically significant differences between vaginal progesterone and cerclage in the reduction of preterm birth or adverse perinatal outcomes.

CONCLUSION: Vaginal progesterone and cerclage are equally effective for preventing preterm birth and improving perinatal outcomes in women with a singleton gestation, previous spontaneous preterm birth, and a midtrimester sonographic short cervix. The choice of treatment will depend on adverse events and cost-effectiveness of interventions and patient/physician's preferences.

\section{Keywords}

admission to neonatal intensive care unit; birthweight < $1500 \mathrm{~g}$; cervical length; cervical stitch; perinatal mortality; prematurity; progestin; progestogens; recurrent preterm birth; transvaginal ultrasound; uterine cervix

Worldwide, an estimated $11.1 \%$ of all live births in 2010 were delivered preterm (14.9 million babies). ${ }^{1}$ In the United States, the preterm birth rate had declined steadily from 2007 to 2014. In 2016, the rate of preterm birth rose to $9.85 \%$, a $2 \%$ rise from 2015 and the second straight year of increase for this rate. ${ }^{2}$

Complications of preterm birth are the leading cause of neonatal mortality, responsible for $35 \%$ of the world's 2.6 million deaths that occurred in $2016 .{ }^{3}$ In addition to its contribution to neonatal and child morbidity and mortality, preterm birth has lifelong effects on neurodevelopmental functioning such as increased risk of cerebral palsy, intellectual disability, visual and hearing impairments, and an increased risk of chronic disease in adulthood. ${ }^{4-11}$

It is widely accepted that preterm birth is a syndrome caused by several pathological processes such as infection, vascular and decidual disorders, uterine overdistension, breakdown of maternal-fetal tolerance, a decline in progesterone action, and cervical disease. ${ }^{12-14}$ A previous spontaneous preterm birth is a well-known risk factor for recurrent spontaneous preterm delivery. ${ }^{15-27}$ A recent meta-analysis reported that the overall risk of recurrent spontaneous preterm birth $<37$ weeks of gestation was $30 \% .{ }^{28} \mathrm{~A}$ short cervix, conventionally defined as a transvaginal sonographic cervical length $\_5 \mathrm{~mm}$ in the midtrimester of pregnancy, is also an important risk factor for spontaneous preterm delivery and has emerged as one of the strongest and most consistent predictors of preterm birth in asymptomatic women with a singleton or twin gestation. ${ }^{29-67}$ 
The combination of previous spontaneous preterm birth and a short cervix markedly increases the risk of recurrent spontaneous preterm birth. Indeed, among women with a previous spontaneous preterm birth, the risk of recurrent spontaneous preterm birth is about 3 -fold higher in those with a cervical length $\_5 \mathrm{~mm}$ than in those with a cervical length $>25$ $\mathrm{mm}$ in the midtrimester. ${ }^{68,69}$

Vaginal progesterone administration ${ }^{70-81}$ and the placement of a cervical cerclage ${ }^{71,75,82-88}$ have been proposed for preventing preterm birth in patients with a singleton gestation, previous spontaneous preterm birth, and a sonographic short cervix. In 2011, an individual patient data (IPD) meta-analysis evaluated the efficacy of cerclage for the prevention of preterm birth and perinatal morbidity and mortality in asymptomatic women with a singleton gestation, previous spontaneous preterm birth, and a cervical length $<25 \mathrm{~mm}$ before 24 weeks of gestation. ${ }^{82}$ Cerclage, compared to no cerclage, significantly decreased the risk of preterm birth $<37,<35,<32$, and $<28$ weeks of gestation, composite perinatal morbidity and mortality, and birthweight $<1500 \mathrm{~g}$.

In 2013, another IPD meta-analysis reported that vaginal progesterone administration to women with the same characteristics was associated with a significant reduction in the risk of preterm birth <32 weeks of gestation, composite perinatal morbidity and mortality, composite neonatal morbidity, and admission to the neonatal intensive care unit (NICU). ${ }^{71}$ Data from these 2 IPD meta-analyses were used to perform an adjusted indirect comparison meta-analysis of vaginal progesterone vs cerclage using placebo/ no cerclage as the common comparator. ${ }^{71}$ This indirect meta-analysis did not show statistically significant differences between vaginal progesterone and cerclage in the reduction of preterm birth or adverse perinatal outcomes in women with a singleton gestation, previous spontaneous preterm birth, and a midtrimester cervical length $<25 \mathrm{~mm} .{ }^{71}$ It was concluded that both interventions are equally efficacious for preventing preterm birth and adverse perinatal outcomes in these patients. To date, only 2 small randomized controlled trials have directly compared vaginal progesterone and cerclage in women with these characteristics. ${ }^{89,90}$ However, the trials lacked power to detect group differences.

In 2016, the OPPTIMUM study, which tested the effect of vaginal progesterone in women at risk for preterm birth, reported that vaginal progesterone did not reduce the risk of preterm birth or neonatal morbidity and mortality in the entire population or in the subgroup of women with a cervical length $\_25 \mathrm{~mm} .{ }^{91}$ Therefore, it is necessary to reassess the efficacy of vaginal progesterone in women with a singleton gestation, previous spontaneous preterm birth, and a midtrimester sonographic short cervix and to update the adjusted indirect comparison meta-analysis of vaginal progesterone vs cerclage in the patients with these characteristics. Adjusted indirect comparisons offer a unique opportunity to compare competing interventions. Their results usually, but not always, agree with the results of headto-head randomized controlled trials. ${ }^{92-98}$ When direct evidence from randomized controlled trials is lacking or insufficient, the adjusted indirect comparison meta-analysis may provide useful information on the relative efficacy of the competing interventions.

The aim of this study was to compare the efficacy of vaginal progesterone and cerclage in preventing preterm birth and adverse perinatal outcomes in women with a singleton 
gestation, previous spontaneous preterm birth, and a midtrimester sonographic short cervix by using adjusted indirect comparison meta-analytic techniques.

\section{Materials and Methods}

This updated indirect comparison meta-analysis was performed according to the Preferred Reporting Items for Systematic Reviews and Meta-Analyses (PRISMA) guidelines ${ }^{99}$ and suggested guidelines for IPD ${ }^{100}$ and indirect meta-analyses. ${ }^{101}$ To ensure consistency, we used the same methodology as in our previous study. ${ }^{71}$ The study protocol was prospectively registered with the PROSPERO database of systematic reviews (CRD42017077311). Two of the authors (A.C.-A. and R.R.) independently retrieved and reviewed studies for eligibility, assessed their risk of bias, and extracted data. All disagreements encountered in the review process were resolved through consensus.

\section{Literature search and study selection}

In our previous indirect comparison meta-analysis, ${ }^{71}$ MEDLINE, EMBASE, CINAHL, LILACS, the Cochrane Central Register of Controlled Trials, and research registers of ongoing trials were searched from the inception of each database to Oct. 31, 2012. An updated literature search was undertaken in these databases from Nov. 1, 2012, to March 31, 2018, using a combination of key words and text words related to progesterone, cervical cerclage, and preterm birth to identify randomized controlled trials comparing vaginal progesterone vs placebo/no treatment, or cerclage vs no cerclage for the prevention of preterm birth in women with a singleton gestation. Google Scholar, proceedings of congresses/meetings on maternal-fetal medicine, reference lists of identified studies, and review articles were also searched. There were no language restrictions.

Trials were eligible if the primary aim of the study was to prevent preterm birth in asymptomatic women with a singleton gestation, previous spontaneous preterm birth, and a sonographic short cervix (cervical length $<25 \mathrm{~mm}$ ) in the midtrimester or to prevent preterm birth in women with other characteristics but for whom outcomes were available in those with a singleton gestation, previous spontaneous preterm birth, and a pre-randomization cervical length $<25 \mathrm{~mm}$.

Trials were excluded if they (1) were quasirandomized, (2) assessed vaginal progesterone in women with threatened or arrested preterm labor, second-trimester bleeding, or premature rupture of membranes, (3) evaluated vaginal progesterone administration in the first trimester to prevent miscarriage, (4) assessed history-indicated cerclage (placed for the sole indication of poor obstetric history), physical examination-indicated cerclage (placed for second-trimester cervical dilatation), or compared different cerclage techniques or outpatient cerclage vs inpatient cerclage, or (5) did not provide data for women with a singleton gestation, previous spontaneous preterm birth, and a cervical length $<25 \mathrm{~mm}$ in the midtrimester.

\section{Data collection and extraction}

For the IPD meta-analysis that compared vaginal progesterone vs placebo, we contacted the principal investigators of eligible trials to request access to the data. Authors were supplied 
with a data extraction sheet and requested to supply anonymized data about baseline characteristics, interventions, and outcomes for each randomized patient in the trial. Data provided by the investigators were systematically checked for completeness, duplication, consistency, feasibility, and integrity of randomization. Inconsistencies or missing data were discussed with the authors and corrections were made when deemed necessary. Finally, data on participant characteristics and outcomes were extracted for women with a singleton gestation, previous spontaneous preterm birth, and a cervical length $<25 \mathrm{~mm}$ and were uploaded to the main study database.

We also extracted data from each study on its characteristics and details of interventions. For studies comparing cerclage vs no cerclage, data on proportions and relative risks (RRs) with 95\% confidence intervals (CIs) for each outcome measure were extracted from the IPD meta-analysis by Berghella et al, ${ }^{82}$ which used a similar approach to that described above.

\section{Outcome measures}

The prespecified primary outcomes were preterm birth $<35$ weeks of gestation and perinatal mortality. Secondary outcomes were preterm birth $<37$, $<32$, and $<28$ weeks of gestation; respiratory distress syndrome; grade III/IV intraventricular hemorrhage; necrotizing enterocolitis; neonatal sepsis; bronchopulmonary dysplasia; composite neonatal morbidity (defined as the occurrence of any of the abovementioned neonatal morbidities); composite perinatal morbidity and mortality (defined as the occurrence of any of the above-mentioned neonatal morbidities or perinatal death); admission to the NICU; and birthweight $<2500 \mathrm{~g}$ and $<1500 \mathrm{~g}$.

\section{Risk of bias assessment}

Assessments of the risk of bias for included trials were done according to the 7 domains outlined in the Cochrane Handbook for Systematic Reviews of Interventions (random sequence generation, allocation concealment, blinding of participants and personnel, blinding of outcome assessment, incomplete outcome data, selective reporting, and other bias). ${ }^{102}$ This tool categorizes studies by a low, unclear, or high risk of bias in each domain.

\section{Statistical analysis}

For studies comparing vaginal progesterone vs placebo, we performed an IPD meta-analysis using a 2-stage approach. In the first stage, estimates of effect were derived from the IPD for each trial, and in the second stage, these were combined using standard methods for metaanalyses of aggregate data to give a pooled RR with $95 \% \mathrm{CI} .{ }^{103} \mathrm{~A}$ similar approach was used in the IPD meta-analysis of trials that evaluated cerclage vs no cerclage. ${ }^{82}$

Heterogeneity of the results among studies was tested with the quantity $\mathbf{I}^{2}$ in the IPD metaanalysis of vaginal progesterone vs placebo ${ }^{104}$ and the Mantel-Haenszel Q statistics in the IPD meta-analysis of cerclage vs no cerclage. Results from individual studies were pooled using a fixed-effects model if substantial statistical heterogeneity was not present ( $\mathbf{I}^{2} \mathbf{3 0 \%}$ or $P \geq .10$ for Mantel-Haenszel Q statistics). Otherwise, random-effects models were used to pool data across studies. 
Number needed to treat with $95 \%$ CI was calculated where meta-analysis of dichotomous outcomes revealed a statistically significant beneficial or harmful effect of vaginal progesterone or cerclage. ${ }^{105} \mathrm{We}$ also planned to explore potential sources of heterogeneity and to assess publication and related biases if at least 10 studies were included in a metaanalysis, but these analyses were not undertaken because of the limited number of trials included in the review.

The adjusted indirect comparison meta-analysis of vaginal progesterone vs cerclage was performed according to the method of Bucher et al. ${ }^{106} \mathrm{In}$ this approach, the direct comparisons A vs B and C vs B with the common comparator link B are used to yield an indirect comparison of A vs $\mathrm{C}$. Because vaginal progesterone and cerclage have been compared to placebo and no cerclage, respectively, indirect comparison was enabled by the common placebo/no cerclage arms. An extension of the method of Bucher et $\mathrm{al}^{106}$ was used to convert the summary estimates (lnRRs) and measures of uncertainty (variances) from the 2 meta-analyses into an RR $(95 \% \mathrm{CI})$ that represented the difference between vaginal progesterone and cerclage. This method is well validated and recommended as the preferred method for indirect comparison, superior to other methods because it preserves the randomization and retains the methodological properties of the randomized controlled trials. $92,94,96,107$

We carried out a subgroup analysis (direct and adjusted indirect comparisons) for women with a cervical length $<16 \mathrm{~mm}$. Moreover, we performed a sensitivity analysis (direct and adjusted indirect comparisons) to explore the impact of cointerventions on the direction and size of effect for preterm birth and perinatal mortality. In this sensitivity analysis, we excluded women who received $17 a$-hydroxyprogesterone caproate (17-OHPC) or vaginal progesterone in trials that compared cerclage vs no cerclage and women who received a cerclage in studies that compared vaginal progesterone to placebo. This analysis was performed because it is unclear whether the effects of progesterone and cerclage are additive in women with a singleton gestation, previous spontaneous preterm birth, and a short cervix. A prespecified sensitivity analysis to explore the impact of study quality on results was not carried out because all trials were considered to be at low risk of bias. Subgroup and sensitivity analyses were performed only for the outcomes measures of preterm birth $<35$ and $<32$ weeks of gestation and perinatal mortality.

One author (A.C.-A.) conducted all statistical analyses using Review Manager software (version 5.3.5; Nordic Cochrane Centre, Copenhagen, Denmark) to perform direct metaanalyses and Indirect Treatment Comparison software (version 1.0; Canadian Agency for Drugs and Technologies in Health, Ottawa, Canada) to perform adjusted indirect comparison meta-analyses.

This study was exempted from review by the Human Investigation Committee Administration Office of Wayne State University because all included studies were published previously and had each received local Institutional Review Board approvals and informed consent from participants. 


\section{Results}

\section{Results of the search}

Our previous search yielded 32 potentially relevant studies, of which 9 were included (4 comparing vaginal progesterone vs placebo ${ }^{108-111}$ and 5 comparing cerclage vs no cerclage $\left.^{112-116}\right)$. The updated search identified 4 randomized controlled trials that compared vaginal progesterone vs placebo ${ }^{91,117-119}$ and $1^{120}$ that compared cerclage vs no cerclage in singleton gestations with the aim of preventing preterm birth and/or adverse perinatal outcomes. Three of the four studies that assessed vaginal progesterone vs placebo were excluded because they included women without previous spontaneous preterm birth ${ }^{117}$ or women with a short cervix (cervical length $\mathcal{S} 5 \mathrm{~mm}$ ) who underwent cerclage before randomization, ${ }^{118}$ and data on cervical length were not collected before randomization. ${ }^{119} \mathrm{~A}$ trial that assessed cerclage vs no cerclage in singleton gestations with a short cervix (cervical length $<25 \mathrm{~mm}$ ) was excluded because data on 14 women with a previous preterm birth that were included in this study could not be obtained. ${ }^{120}$ Thus, only one new trial (the OPPTI-MUM study ${ }^{91}$ ) was included in this updated indirect comparison meta-analysis. In total, 10 trials met the inclusion criteria that provided data for 769 women with a singleton gestation, previous spontaneous preterm birth, and a cervical length $<25 \mathrm{~mm}$ at midtrimester.

\section{Characteristics and risk of bias of included studies}

Table 1 depicts the main characteristics of the 10 studies included in this indirect comparison meta-analysis. Five double-blind, placebo-controlled trials, including 265 women, compared vaginal progesterone vs placebo..$^{91,108-111}$ Two studies evaluated the use of vaginal progesterone in women with a short cervix (cervical length $₫ 5 \mathrm{~mm}{ }^{108}$ and cervical length between 10 and $20 \mathrm{~mm}^{111}$ ); 1 in women with a previous spontaneous preterm birth; ${ }^{109} 1$ in women with a previous spontaneous preterm birth, uterine malformations, or twin gestation; 110 and the remainder in women with a previous spontaneous preterm birth, short cervix (cervical length $\_5 \mathrm{~mm}$ ), or a positive fetal fibronectin test combined with other clinical risk factors for preterm birth. ${ }^{91}$ The daily dose of vaginal progesterone used in the trials varied from 90 to $200 \mathrm{mg}$, and the treatment was administered from 18-25 to 34-36 weeks of gestation. Thirty women ( 25 in the study by Norman et $\mathrm{al}^{91}$ and 5 in the study by Hassan et $\mathrm{al}^{111}$ ) underwent a cerclage after randomization.

Five trials, including 504 women, compared cerclage vs no cerclage in women with a sonographic short cervix. ${ }^{12-116}$ Gestational age at cervical length screening varied between 14 and 24 weeks of gestation. Four trials used the McDonald procedure ${ }^{112,113,115,116}$ and 1 used the Shirodkar technique. ${ }^{114}$ Rescue cerclage in women allocated to the no cerclage group was allowed in 3 studies based on physical examination ${ }^{116}$ or on ultrasonographic cervical changes. ${ }^{12,113}$ In the trial by Owen et al, ${ }^{11699}$ women received $17-$ OHPC and 1 received vaginal progesterone. ${ }^{121}$

All 10 studies included in the meta-analysis had adequate random sequence generation and allocation concealment, were free of selective outcome reporting, and had adequate handling of incomplete outcome data. In the 5 trials that evaluated vaginal progesterone, there was blinding of participants, health care providers, and outcome assessors. In the 5 trials that 
evaluated cerclage, blinding of participants and personnel was not feasible because of the nature of the intervention. It was unclear whether outcome assessors were blinded from knowledge of which intervention a participant received. However, we considered that assessment of most outcomes included in our review were objective in nature and thus unlikely to be influenced by a lack of blinding in studies that evaluated cerclage. All but one study ${ }^{91}$ had no obvious risk of other biases. In fact, the study by Norman et $\mathrm{al}^{91}$ was at high risk of compliance bias because only $66 \%$ of patients with a cervical length $\_5 \mathrm{~mm}$ had a compliance $\geq 80 \%$, which can affect the trial's statistical power to detect the effects of intervention. ${ }^{122}$ Overall, all 10 trials were considered to be at low risk of bias.

\section{Comparability of the vaginal progesterone and cerclage trials}

All women included in this updated indirect comparison meta-analysis ( 265 from trials that evaluated vaginal progesterone and 504 from trials that evaluated cerclage) had a singleton gestation, previous spontaneous preterm birth, and a cervical length $<25 \mathrm{~mm}$ detected in the midtrimester (most at 16-24 weeks of gestation). The percentage of patients with a cervical length $<16 \mathrm{~mm}$ was $42.6 \%$ in the trials that evaluated vaginal progesterone and $30.6 \%$ in the trials that evaluated cerclage.

Women included in the trials that evaluated vaginal progesterone had a mean (SD) age and body mass index of $27.0(6.3)$ years and $29.4(6.5) \mathrm{kg} / \mathrm{m}^{2}$, respectively, and black and white women represented $75 \%$ of the study population. The sociodemographic characteristics of women included in the IPD meta-analysis that evaluated cerclage were not reported in the study publication. ${ }^{82}$ However, patient characteristics reported in individual trials of cerclage were comparable to those of patients who participated in trials of vaginal progesterone. For example, in the study by Owen et al, ${ }^{116}$ the largest that assessed cerclage, black and white women represented $75 \%$ of the study population and the mean age and body mass index were 26.5 years and $29.6 \mathrm{~kg} / \mathrm{m}^{2}$, respectively. Finally, the rates of most outcome measures in the control groups of trials that evaluated vaginal progesterone and cerclage were similar (Table 2).

\section{Direct comparisons}

Vaginal progesterone administration to patients with a singleton gestation, previous spontaneous preterm birth, and a midtrimester cervical length $<25 \mathrm{~mm}$ significantly reduced the risk of preterm birth $<35$ weeks (RR, $0.68 ; 95 \%$ CI, 0.50-0.93) and $<32$ weeks of gestation (RR, 0.60; 95\% CI, 0.39-0.92), neonatal sepsis (RR, 0.38; 95\% CI, 0.15-0.96), composite neonatal morbidity (RR, $0.29 ; 95 \% \mathrm{CI}, 0.11-0.81$ ), composite perinatal morbidity and mortality (RR, 0.43 ; 95\% CI, 0.20-0.94), and admission to the NICU (RR, 0.46 ; $95 \%$ CI, 0.30-0.70) (Table 2).

The use of cerclage in women with a singleton gestation, previous spontaneous preterm birth, and a cervical length $<25 \mathrm{~mm}$ in the midtrimester was associated with a significantly lower risk of preterm birth <37 weeks (RR, 0.70; 95\% CI, 0.58-0.83), <35 weeks (RR, 0.70; 95\% CI, 0.55-0.89), <32 weeks (RR, 0.66; 95\% CI, 0.48-0.91), and <28 weeks of gestation (RR, $0.64 ; 95 \%$ CI, 0.43-0.96), composite perinatal morbidity and mortality (RR, $0.64 ; 95 \%$ CI, 0.45-0.91), and birthweight <1500 g (RR, 0.64; 95\% CI, 0.45-0.90). Numbers needed to 
treat for vaginal progesterone varied from 5 to 16 (median, 7) and for cerclage from 6 to 14 (median, 11).

Both vaginal progesterone and cerclage were associated with a nonsignificant decrease in the risk of perinatal mortality (RR, 0.63 ; $95 \% \mathrm{CI}, 0.26-1.56$ for vaginal progesterone, and $\mathrm{RR}, 0.65 ; 95 \% \mathrm{CI}, 0.40-1.07$ for cerclage) and respiratory distress syndrome (RR, 0.38; 95\% CI, 0.13-1.07 for vaginal progesterone, and RR, $0.61,95 \%$ CI, $0.32-1.19$ for cerclage). The rates of grade III/IV intraventricular hemorrhage, necrotizing enterocolitis, bronchopulmonary dysplasia, and birthweight $<2500 \mathrm{~g}$ did not differ significantly between the vaginal progesterone and placebo groups and between the cerclage and no cerclage groups. There was no substantial heterogeneity in any of the meta-analyses that compared vaginal progesterone vs placebo and cerclage vs no cerclage.

\section{Indirect comparison}

Adjusted indirect comparison meta-analyses showed no statistically significant differences between vaginal progesterone and cerclage in preventing preterm birth $<35$ weeks of gestation (RR, 0.97; 95\% CI, 0.66-1.44; $P=.93$ ) and perinatal death (RR, 0.97; 95\% CI, $0.35-2.69 ; P=.96$ ) (Table 3 ). There were no significant differences between vaginal progesterone and cerclage for any of the secondary outcome measures. Estimated RRs ranged from 0.48 for composite neonatal morbidity (favoring vaginal progesterone) to 1.79 for grade III/IV intraventricular hemorrhage (favoring cerclage), but all 95\% CIs included 1 with most values of $P>.75$. These results indicate that vaginal progesterone and cerclage are not significantly different in terms of efficacy for reducing the risk of preterm birth and adverse perinatal outcomes.

\section{Subgroup and sensitivity analyses}

Among women with a cervical length $<16 \mathrm{~mm}$, both vaginal progesterone and cerclage were associated with a significant reduction in the risk of preterm birth $<35$ weeks of gestation (Table 4). Moreover, cerclage significantly reduced the rate of preterm birth $<32$ weeks of gestation in these patients. Vaginal progesterone and cerclage significantly decreased the risk of preterm birth $<35$ and $<32$ weeks of gestation in a sensitivity analysis that excluded both patients who received progestogens in trials that evaluated cerclage and those in whom a cerclage was placed in trials that evaluated vaginal progesterone. No statistically significant differences were observed in the adjusted indirect comparisons between vaginal progesterone and cerclage in subgroup and sensitivity analyses.

\section{Comment}

\section{Principal findings of the study}

The results of this updated indirect comparison meta-analysis indicate that vaginal progesterone and cerclage are equally efficacious in preventing preterm birth in women with a singleton gestation, previous spontaneous preterm birth, and a sonographic short cervix. Indeed, vaginal progesterone significantly decreased the risk of preterm birth $<35$ and $<32$ weeks of gestation, neonatal sepsis, composite neonatal morbidity, composite perinatal morbidity and mortality, and admission to NICU as compared to placebo. On the other hand, 
cerclage was associated with a significant reduction in the risk of preterm birth $<37,<35$, $<32$, and $<28$ weeks of gestation, composite perinatal morbidity and mortality, and birthweight $<1500 \mathrm{~g}$ when compared to no cerclage. Both interventions were associated with a nonsignificant $\sim 36 \%$ reduction in the rate of perinatal death. Adjusted indirect comparisons showed that there were no significant differences between the efficacy of vaginal progesterone and cerclage in the prevention of preterm birth or adverse perinatal outcomes. These findings were consistent with sensitivity analyses that excluded patients who received cointerventions. Finally, a subgroup analysis revealed that both interventions significantly reduced the rate of preterm birth $<35$ weeks of gestation in women with a cervical length $<16 \mathrm{~mm}$.

Thus far, only 2 small randomized controlled trials have directly compared vaginal progesterone and cerclage in women with a singleton gestation, previous spontaneous preterm birth, and a short cervix. ${ }^{89,90}$ Ionescu et al ${ }^{89}$ performed a randomized controlled trial, reported in abstract form only, in which women with a singleton gestation, previous preterm birth, and a cervical length $<25 \mathrm{~mm}$ before 24 weeks of gestation were randomly assigned to receive either vaginal progesterone $200 \mathrm{mg} / \mathrm{d}(\mathrm{n}=46)$ or cerclage $(n=46)$. The mean gestational age at delivery was not significantly different between women allocated to receive vaginal progesterone (31.5 weeks) and those allocated to receive a cerclage (32.9 weeks). Chandiramani et $\mathrm{al}^{90}$ conducted a randomized controlled trial that compared vaginal progesterone $400 \mathrm{mg} / \mathrm{d}(\mathrm{n}=17)$ vs cerclage $(\mathrm{n}=19)$ in women with a singleton gestation, at least 1 previous spontaneous preterm birth, and a cervical length $<25 \mathrm{~mm}$ before 24 weeks of gestation. There was no statistically significant difference in mean gestational age at delivery between the vaginal progesterone $(31.5 \pm 9.0$ weeks $)$ and cerclage $(33.7 \pm 7.7$ weeks) groups $(P=.23)$.

The authors of these trials provided additional information to a Cochrane review that assessed the use of cerclage in women with a singleton gestation at high risk for preterm birth, ${ }^{123}$ which allowed the performance of direct comparison meta-analyses between vaginal progesterone and cerclage in women with a singleton gestation, previous spontaneous preterm birth, and a cervical length $<25 \mathrm{~mm}$ in the midtrimester. In accordance with the results of our indirect comparison meta-analysis, the Cochrane review reported that there were no significant differences between cerclage and vaginal progesterone in the risk of preterm birth <37 weeks (RR, 1.16; 95\% CI, 0.64-2.08), <34 weeks (RR, 1.01; 95\% CI, 0.51-2.01), and <28 weeks of gestation (RR, 0.92; 95\% CI, 0.37-2.27), perinatal mortality (RR, 0.94; 95\% CI, 0.36-2.48), and serious neonatal morbidity (RR, 0.49; 95\% CI, 0.054.52). ${ }^{123}$ However, data from one study ${ }^{89}$ showed that the rates of both preterm premature rupture of membranes and use of tocolytic agents were significantly higher in the cerclage group than in the vaginal progesterone group (17\% vs $2 \%$; RR, 8.00; 95\% CI, 1.04-61.42 for preterm premature rupture of membranes; and $65 \%$ vs $17 \%$; RR, 3.75; 95\% CI, 1.937.29 for use of tocolytic agents).

In the absence of adequately powered, high-quality, randomized controlled trials comparing vaginal progesterone and cerclage, our indirect comparison treatment meta-analysis provides the best available evidence regarding comparative efficacy of the 2 interventions. 


\section{Strengths and limitations}

The main strengths of our study include the following: (1) the rigorous methodology used for performing the indirect comparison meta-analysis; (2) the use of individual patient data from direct comparisons of vaginal progesterone vs placebo and cerclage vs no cerclage for performing indirect comparisons of vaginal progesterone vs cerclage; (3) the low risk of bias for most trials included in the review; (4) the comparability of trial and patient characteristics between studies that evaluated vaginal progesterone and those that evaluated cerclage; (4) the remarkably similar rates of preterm birth and adverse perinatal outcomes found in control groups of trials that evaluated vaginal progesterone and cerclage, making more homogeneous the common comparator placebo/no cerclage in indirect meta-analyses; (5) the absence of statistical heterogeneity in all direct meta-analyses performed; (6) the robustness of the study findings to sensitivity analyses restricted to patients who did not receive cointerventions; and (7) the consistency between the results obtained in our indirect comparison meta-analysis and those obtained in the meta-analysis ${ }^{123}$ of 2 trials that directly compared vaginal progesterone and cerclage.

Some potential limitations must also be considered. First, the OPPTIMUM study ${ }^{91}$ did not collect data on respiratory distress syndrome, the most common complication of preterm birth, which reduced the sample size of meta-analyses for the composite outcomes of neonatal morbidity and perinatal morbidity and mortality in the comparison of vaginal progesterone vs placebo.

Second, data for 14 patients with a singleton gestation, previous preterm birth, and cervical length $<25 \mathrm{~mm}$ who participated in a trial ${ }^{120}$ that compared Shirodkar cerclage, McDonald cerclage, and bed rest (no cerclage) could not be obtained from the investigators. It was not possible to determine how many of these patients had a previous spontaneous preterm birth. In this trial, ${ }^{120} \mathrm{a}$ total of 104 women with no signs of infection or inflammation of the lower genital tract and a cervical length $<25 \mathrm{~mm}$ between 16 and 26 weeks of gestation were randomly allocated to 1 of the 3 groups. Overall, there were no significant differences between the cerclage and no cerclage groups in the risk of preterm birth and adverse perinatal outcomes. It is very unlikely that the significant beneficial effects of cerclage on the risk of preterm birth and perinatal morbidity and mortality become nonsignificant after the inclusion of data from this study in the meta-analyses.

Third, $20 \%$ of women in the control group of trials evaluating cerclage received 17-OHPC compared to none in the control group of trials evaluating vaginal progesterone. This difference could potentially mean that the control groups, which were used as the common comparator, were not similar. Notwithstanding, the sensitivity analysis performed by excluding these patients showed no significant differences in the results obtained with overall meta-analyses. In addition, there is no evidence that 17-OHPC can decrease the risk of preterm birth in women with a singleton gestation and a short cervix. ${ }^{124-126}$

Finally, maternal side effects associated with cerclage use, such as vaginal discharge, infection, and bleeding, were not reported in the IPD meta-analysis that evaluated this intervention, ${ }^{82}$ which precluded comparisons to those reported in trials that evaluated vaginal progesterone. 


\section{Maternal adverse events and long-term childhood outcomes related to interventions}

At the time of translating the results from this updated indirect comparison meta-analysis into practice, some considerations are necessary. Given the apparent similar efficacy between vaginal progesterone and cerclage, differences in maternal adverse events and longterm childhood outcomes are key variables that clinicians and patients with a singleton gestation and previous spontaneous preterm birth should consider when selecting an optimal treatment for a sonographic short cervix in the midtrimester. Cerclage placement has been associated with complications such as rupture of membranes, chorioamnionitis, bleeding, and cervical lacerations. ${ }^{86}$ Additionally, cerclage is a surgical intervention usually performed under general or spinal anesthesia and as such is a risk for surgical complications. The trial by Owen et al, ${ }^{116}$ which contributed $60 \%$ of patients to the IPD meta-analysis that evaluated cerclage, ${ }^{82}$ reported that surgical and anesthetic complications associated with cerclage placement were uncommon. The Cochrane review that assessed the use of cerclage for preventing preterm birth in women with a singleton gestation at high risk for this entity reported that cerclage, compared to no treatment, significantly increased the rates of maternal fever (6\% vs $2 \%$; RR, $2.39,95 \%$ CI, $1.35-4.23)$ and cesarean delivery (18\% vs $15 \%$; RR, 1.19; 95\% CI, 1.01-1.40). ${ }^{123}$ Moreover, cerclage was associated with a nonsignificant increase in the risk of maternal side effects (vaginal discharge, bleeding, or pyrexia not requiring antibiotics; RR, 2.25; 95\% CI, 0.89-5.69).

Several systematic reviews and meta-analyses that evaluated the efficacy and safety of vaginal progesterone for preventing preterm birth in singleton and twin gestations have reported that the rates of maternal adverse events, discontinuation of treatment because of adverse effects, and congenital anomalies did not differ significantly between the vaginal progesterone and placebo/no treatment groups..$^{70,81,127-129}$ With regard to long-term childhood outcomes, current evidence suggests that in utero exposure to vaginal progesterone, administered in a singleton or twin gestation for the prevention of preterm birth, has no harmful effect on neurodevelopmental outcomes at least until 8 years of age. 91,130-134 No studies have reported on long-term neurodevelopmental outcomes in children whose mothers received a cerclage. ${ }^{134}$

\section{Cost-effectiveness of interventions}

Evidence from several studies indicates that the combination of universal transvaginal cervical length screening and vaginal progesterone administration to women with a short cervix is a cost-effective intervention that reduces preterm birth and perinatal morbidity and mortality. ${ }^{135-144}$ Moreover, emerging evidence from recent studies conducted in hospitals located in the United States ${ }^{14-146}$ and 1 Australian state ${ }^{147}$ suggests that the implementation of universal cervical length screening and vaginal progesterone administration to patients with a sonographic short cervix is associated with a significant reduction in the rates of preterm birth. Several of these studies included women with a previous spontaneous preterm birth. ${ }^{135,139,140,142,143,146-148}$

We identified 3 studies, all published in abstract form only, that have evaluated the costeffectiveness of cerclage in women with a short cervix. ${ }^{149-151}$ In 2011, Miller and Grobman ${ }^{149}$ compared 17-OHPC alone vs ultrasonographic cervical length screening with 
cerclage placement for women with a cervical length $<15 \mathrm{~mm}$. This strategy was more costly and less effective than the 17-OHPC-only strategy. The authors concluded that "cervical length screening for possible cerclage placement is not, under most circumstances, a cost-effective strategy to prevent recurrent preterm birth." In 2015 , Eke et al ${ }^{150}$ evaluated the cost-effectiveness of vaginal progesterone compared to cerclage in patients with a sonographically short cervix. Treatment with vaginal progesterone, as compared to cerclage, was associated with a lower incidence of preterm birth and resulted in better efficacy. In $80 \%$ of simulations, vaginal progesterone was less costly in comparison to cerclage. The authors of this study concluded that vaginal progesterone was the most cost-effective strategy in treating women with a short cervix. Finally, Gray et al ${ }^{151}$ performed a decision and cost analysis about serial cervical length screening in women with a singleton gestation and a previous spontaneous preterm birth. Patients with a cervical length $\widehat{\Omega} 5 \mathrm{~mm}$ would be treated with vaginal progesterone, cerclage, or a pessary. This study reported that cervical length screening and treatment with cerclage were not only the most costly strategy but also the most effective in reducing preterm birth.

\section{Clinical practice guidelines}

Currently, the National Institute for Health and Care Excellence ${ }^{74}$ recommends offering either vaginal progesterone or cerclage to women with a singleton gestation, previous spontaneous preterm birth, and a midtrimester cervical length $<25 \mathrm{~mm}$. The International Federation of Gynecology and Obstetrics recommends vaginal progesterone for women with a singleton gestation and a cervical length $\_25 \mathrm{~mm}$, regardless of obstetrical history. ${ }^{73}$ The Society for Maternal-Fetal Medicine ${ }^{84,87,152}$ and the American Congress of Obstetricians and Gynecologists ${ }^{85,86}$ recommend considering the placement of a cerclage in patients with a singleton gestation, previous spontaneous preterm birth, and a cervical length $<25 \mathrm{~mm}$ before 24 weeks of gestation. This recommendation was based mainly on the findings of the IPD meta-analysis that assessed the use of cerclage in women with these characteristics. ${ }^{82} \mathrm{In}$ a recently published viewpoint article, ${ }^{88}$ Dr Vincenzo Berghella, the lead author of the IPD meta-analysis that evaluated the efficacy of cerclage in women with a singleton gestation, previous spontaneous preterm birth, and a cervical length $<25 \mathrm{~mm}$, wrote about his study: “... after 17 years of collaborative research, a meta-analysis of randomized controlled trials on cerclage for singleton gestations with a prior spontaneous preterm birth and with a short transvaginal ultrasound cervical length $<25 \mathrm{~mm}$ before 24 weeks led to new clinical recommendations worldwide. This is an example of the power of meta-analyses, of why I like them and why I think you should like them, too. Many societies rank meta-analyses of randomized controlled trials as the best level of evidence, even above that of a single randomized controlled trial." We strongly agree with Dr Berghella's statement and believe that the same applies to both our updated IPD meta-analysis showing that vaginal progesterone also decreases preterm birth and improves perinatal outcomes in patients with a singleton gestation, previous spontaneous preterm birth, and a cervical length $<25 \mathrm{~mm}$ and our updated adjusted indirect comparison meta-analysis demonstrating that vaginal progesterone and cerclage are equally efficacious in preventing preterm birth in these patients. Therefore, professional/scientific organizations need to revise their recommendations to clinicians, based on the available evidence, and recommend that vaginal progesterone be offered as an alternative to cerclage in patients with a singleton gestation, 
previous spontaneous preterm birth, and a cervical length $<25 \mathrm{~mm}$ before 24 weeks of gestation.

\section{Implications for practice}

In summary, either vaginal progesterone or cerclage can be used to prevent preterm birth and to improve perinatal outcomes in patients with a singleton gestation, previous spontaneous preterm birth, and a midtrimester sonographic short cervix. Thus, other criteria in addition to efficacy may play a role in therapeutic decision making, including maternal adverse events and cost-effectiveness of interventions and the patient and physician's preferences.

\section{Implications for research}

Adequately powered randomized controlled trials directly comparing vaginal progesterone and cerclage would provide the best estimates of efficacy, but such trials would require a large sample size, given the relatively similar efficacy of these interventions. These studies should determine the cost-effectiveness of interventions and assess the long-term effects of these strategies on childhood outcomes. In the interim, we believe that our indirect comparison meta-analysis represents the best available evidence for consideration in guiding clinical practice.

\section{Acknowledgment}

We are grateful to Professor Jane E. Norman and the investigators of the OPPTIMUM trial for providing the individual data for the 107 patients with a previous spontaneous preterm birth and a cervical length $<25 \mathrm{~mm}$. Professor Jane Norman is principal investigator at the Tommy's Centre for Maternal and Fetal Health, Medical Research Council (MRC) Center for Reproductive Health, University of Edinburgh, Edinburgh, United Kingdom. The OPPTIMUM study was funded by the Efficacy and Mechanism Evaluation program, an MRC and National Institute for Health Research partnership, award number G0700452, revised to 09/800/27. The Efficacy and Mechanism Evaluation program is funded by the MRC and the National Institute for Health Research, with contributions from the Chief Scientist Office in Scotland and the National Institute for Social Care and Research in Wales. Professor Jane Norman has no conflict of interest in relation to our meta-analysis of individual patient data and indirect comparison meta-analysis.

The funder had no role in the design or conduct of the study; collection, management, analysis, or interpretation of the data; preparation, review, or approval of the manuscript; or the decision to submit the manuscript for publication.

This research was supported, in part, by the Perinatology Research Branch, Division of Intramural Research, Eunice Kennedy Shriver National Institute of Child Health and Human Development, National Institutes of Health, Department of Health and Human Services.

\section{References}

1. Blencowe H, Cousens S, Oestergaard MZ, et al. National, regional, and worldwide estimates of preterm birth rates in the year 2010 with time trends since 1990 for selected countries: a systematic analysis and implications. Lancet 2012;379:2162-72. [PubMed: 22682464]

2. Martin JA, Hamilton BE, Osterman MJK, Driscoll AK, Drake P. Births: final data for 2016. Natl Vital Stat Rep 2018;67:1.

3. United Nations Inter-Agency Group for Child Mortality Estimation (UN IGME). Levels and trends in child mortality: report 2017, estimates developed by the UN Inter-Agency Group for Child Mortality Estimation. New York: United Nations Children's Fund; 2017.

4. Institute of Medicine, US Committee on Understanding Premature Birth and Assuring Healthy Outcomes. In: Behrman RE, Butler AS, eds. Preterm birth: causes, consequences, and prevention. Washington, DC: National Academies Press; 2007. 
5. Saigal S, Doyle LW. An overview of mortality and sequelae of preterm birth from infancy to adulthood. Lancet 2008;371:261-9. [PubMed: 18207020]

6. Mwaniki MK, Atieno M, Lawn JE, Newton CR. Long-term neurodevelopmental outcomes after intrauterine and neonatal insults: a systematic review. Lancet 2012;379:445-52. [PubMed: 22244654]

7. Parkinson JR, Hyde MJ, Gale C, Santhakumaran S, Modi N. Preterm birth and the metabolic syndrome in adult life: a systematic review and meta-analysis. Pediatrics 2013;131:e1240-63. [PubMed: 23509172]

8. Li S, Zhang M, Tian H, Liu Z, Yin X, Xi B. Preterm birth and risk of type 1 and type 2 diabetes: systematic review and meta-analysis. Obes Rev 2014;15:804-11. [PubMed: 25073871]

9. Manuck TA, Rice MM, Bailit JL, et al. Preterm neonatal morbidity and mortality by gestational age: a contemporary cohort. Am J Obstet Gynecol 2016;215:103e1-14.

10. Smith DD, Miller R, Gyamfi-Bannerman C. Risk of cerebral palsy by gestational age epoch. Am J Obstet Gynecol 2016;214:S180.

11. Chevallier M, Debillon T, Pierrat V, et al. Leading causes of preterm delivery as risk factors for intraventricular hemorrhage in very preterm infants: results of the EPIPAGE 2 cohort study. Am J Obstet Gynecol 2017;216:518.e1-12. [PubMed: 28104401]

12. Romero R Prenatal medicine: the child is the father of the man. 1996. J Matern Fetal Neonatal Med 2009;22:636-9. [PubMed: 19736614]

13. Romero R, Espinoza J, Kusanovic JP, et al. The preterm parturition syndrome. BJOG 2006;113(Suppl 3):17-42.

14. Romero R, Dey SK, Fisher SJ. Preterm labor: one syndrome, many causes. Science 2014;345:7605. [PubMed: 25124429]

15. Asrat T, Lewis DF, Garite TJ, et al. Rate of recurrence of preterm premature rupture of membranes in consecutive pregnancies. Am J Obstet Gynecol 1991;165:1111-5. [PubMed: 1951524]

16. Ananth CV, Getahun D, Peltier MR, Salihu HM, Vintzileos AM. Recurrence of spontaneous vs medically indicated preterm birth. Am J Obstet Gynecol 2006;195:643-50. [PubMed: 16949395]

17. Goldenberg RL, Andrews WW, Faye-Petersen O, Cliver S, Goepfert AR, Hauth JC. The Alabama Preterm Birth Project: placental histology in recurrent spontaneous and indicated preterm birth. Am J Obstet Gynecol 2006;195:792-6. [PubMed: 16846583]

18. Mazaki-Tovi S, Romero R, Kusanovic JP, et al. Recurrent preterm birth. Semin Perinatol 2007;31:142-58. [PubMed: 17531896]

19. Esplin MS, O'Brien E, Fraser A, et al. Estimating recurrence of spontaneous preterm delivery. Obstet Gynecol 2008;112:516-23. [PubMed: 18757647]

20. Crane JM, Hutchens D. Use of transvaginal ultrasonography to predict preterm birth in women with a history of preterm birth. Ultrasound Obstet Gynecol 2008;32:640-5. [PubMed: 18816494]

21. Getahun D, Strickland D, Ananth CV, et al. Recurrence of preterm premature rupture of membranes in relation to interval between pregnancies. Am J Obstet Gynecol 2010;202: 570.e1-6. [PubMed: 20132922]

22. Manuck TA, Henry E, Gibson J, et al. Pregnancy outcomes in a recurrent preterm birth prevention clinic. Am J Obstet Gynecol 2011;204:320.e1-6. [PubMed: 21345407]

23. Gonzalez-Quintero VH, Cordova YC, Istwan NB, et al. Influence of gestational age and reason for prior preterm birth on rates of recurrent preterm delivery. Am J Obstet Gynecol 2011;205:275.e15. [PubMed: 22071063]

24. Laughon SK, Albert PS, Leishear K, Mendola P. The NICHD Consecutive Pregnancies Study: recurrent preterm delivery by subtype. Am J Obstet Gynecol 2014;210:131.e1-8. [PubMed: 24036403]

25. Drassinower D, Običan SG, Siddiq Z, Heller D, Gyamfi-Bannerman C, Friedman AM. Does the clinical presentation of a prior preterm birth predict risk in a subsequent pregnancy? Am J Obstet Gynecol 2015;213:686.e1-7. [PubMed: 26215326]

26. Yang J, Baer RJ, Berghella V, et al. Recurrence of preterm birth and early term birth. Obstet Gynecol 2016;128:364-72. [PubMed: 27400000] 
27. Koullali B, Ravelli ACJ, Kazemier BM, Pajkrt E, Mol BWJ, Oudijk MA. Recurrence rate of spontaneous preterm birth. Am J Obstet Gynecol 2016;214:S443-4.

28. Phillips C, Velji Z, Hanly C, Metcalfe A. Risk of recurrent spontaneous preterm birth: a systematic review and meta-analysis. BMJ Open 2017;7:e015402.

29. Andersen HF, Nugent CE, Wanty SD, Hayashi RH. Prediction of risk for preterm delivery by ultrasonographic measurement of cervical length. Am J Obstet Gynecol 1990;163: 859-67. [PubMed: 2206073]

30. Iams JD, Goldenberg RL, Meis PJ, et al. The length of the cervix and the risk of spontaneous premature delivery. N Engl J Med 1996;334: 567-72. [PubMed: 8569824]

31. Goldenberg RL, Iams JD, Miodovnik M, et al. The preterm prediction study: risk factors in twin gestations. National Institute of Child Health and Human Development Maternal-Fetal Medicine Units Network. Am J Obstet Gynecol 1996;175: 1047-53. [PubMed: 8885774]

32. Imseis HM, Albert TA, Iams JD. Identifying twin gestations at low risk for preterm birth with a transvaginal sonographic cervical measurement at 24 to 26 weeks' gestation. Am J Obstet Gynecol 1997;177:1149-55. [PubMed: 9396911]

33. Wennerholm UB, Holm B, Mattsby-Baltzer I, et al. Fetal fibronectin, endotoxin, bacterial vaginosis and cervical length as predictors of preterm birth and neonatal morbidity in twin pregnancies. Br J Obstet Gynaecol 1997;104: 1398-404. [PubMed: 9422019]

34. Berghella V, Tolosa JE, Kuhlman K, Weiner S, Bolognese RJ, Wapner RJ. Cervical ultrasonography compared with manual examination as a predictor of preterm delivery. Am $\mathbf{J}$ Obstet Gynecol 1997;177:723-30. [PubMed: 9369810]

35. Grisaru-Granovsky S, Farine D, Barrett J, et al. Is a single ultrasound measurement of cervical length a predictor of the risk of preterm delivery in multifetal pregnancy? Am J Obstet Gynecol 1998;178:191S.

36. Hassan SS, Romero R, Berry SM, et al. Patients with an ultrasonographic cervical length $<$ or $=15$ $\mathrm{mm}$ have nearly a $50 \%$ risk of early spontaneous preterm delivery. Am J Obstet Gynecol 2000;182:1458-67. [PubMed: 10871466]

37. Yang JH, Kuhlman K, Daly S, Berghella V. Prediction of preterm birth by second trimester cervical sonography in twin pregnancies. Ultrasound Obstet Gynecol 2000;15:288-91. [PubMed: 10895446]

38. Guzman ER, Walters C, O'Reilly-Green C, et al. Use of cervical ultrasonography in prediction of spontaneous preterm birth in twin gestations. Am J Obstet Gynecol 2000;183: 1103-7. [PubMed: 11084549]

39. Soriano D, Weisz B, Seidman DS, et al. The role of sonographic assessment of cervical length in the prediction of preterm birth in primigravidae with twin gestation conceived after infertility treatment. Acta Obstet Gynecol Scand 2002;81:39-43. [PubMed: 11942885]

40. Vayssière C, Favre R, Audibert F, et al. Cervical length and funneling at 22 and 27 weeks to predict spontaneous birth before 32 weeks in twin pregnancies: a French prospective multicenter study. Am J Obstet Gynecol 2002;187:1596-604. [PubMed: 12501070]

41. Honest H, Bachmann LM, Coomarasamy A, Gupta JK, Kleijnen J, Khan KS. Accuracy of cervical transvaginal sonography in predicting preterm birth: a systematic review. Ultrasound Obstet Gynecol 2003;22:305-22. [PubMed: 12942506]

42. Owen J, Yost N, Berghella V, et al. Can shortened midtrimester cervical length predict very early spontaneous preterm birth? Am J Obstet Gynecol 2004;191:298-303. [PubMed: 15295382]

43. Gibson JL, Macara LM, Owen P, Young D, Macauley J, Mackenzie F. Prediction of preterm delivery in twin pregnancy: a prospective, observational study of cervical length and fetal fibronectin testing. Ultrasound Obstet Gynecol 2004;23:561-6. [PubMed: 15170796]

44. Sperling L, Kiil C, Larsen LU, et al. How to identify twins at low risk of spontaneous preterm delivery. Ultrasound Obstet Gynecol 2005;26: 138-44. [PubMed: 16038015]

45. Fait G, Har-Toov J, Gull I, Lessing JB, Jaffa A, Wolman I. Cervical length, multifetal pregnancy reduction, and prediction of preterm birth. J Clin Ultrasound 2005;33: 329-32. [PubMed: 16196008] 
46. Arabin B, Roos C, Kollen B, van Eyck J. Comparison of transvaginal sonography in recumbent and standing maternal positions to predict spontaneous preterm birth in singleton and twin pregnancies. Ultrasound Obstet Gynecol 2006;27:377-86. [PubMed: 16514620]

47. To MS, Skentou CA, Royston P, Yu CK, Nicolaides KH. Prediction of patient-specific risk of early preterm delivery using maternal history and sonographic measurement of cervical length: a population-based prospective study. Ultrasound Obstet Gynecol 2006;27:362-7. [PubMed: 16565989]

48. To MS, Fonseca EB, Molina FS, Cacho AM, Nicolaides KH. Maternal characteristics and cervical length in the prediction of spontaneous early preterm delivery in twins. Am J Obstet Gynecol 2006;194:1360-5. [PubMed: 16647922]

49. Crane JM, Hutchens D. Transvaginal sonographic measurement of cervical length to predict preterm birth in asymptomatic women at increased risk: a systematic review. Ultrasound Obstet Gynecol 2008;31:579-87. [PubMed: 18412093]

50. Klein K, Gregor H, Hirtenlehner-Ferber K, et al. Prediction of spontaneous preterm delivery in twin pregnancies by cervical length at midgestation. Twin Res Hum Genet 2008;11:552-7. [PubMed: 18828739]

51. Fox NS, Saltzman DH, Klauser CK, Peress D, Gutierrez CV, Rebarber A. Prediction of spontaneous preterm birth in asymptomatic twin pregnancies with the use of combined fetal fibronectin and cervical length. Am J Obstet Gynecol 2009;201:313.e1-5. [PubMed: 19733285]

52. Honest H, Forbes CA, Durée KH, et al. Screening to prevent spontaneous preterm birth: systematic reviews of accuracy and effectiveness literature with economic modelling. Health Technol Assess 2009; 13:1-627.

53. Domin CM, Smith EJ, Terplan M. Transvaginal ultrasonographic measurement of cervical length as a predictor of preterm birth: a systematic review with meta-analysis. Ultrasound Q 2010;26:241-8. [PubMed: 21084959]

54. Conde-Agudelo A, Romero R, Hassan SS, Yeo L. Transvaginal sonographic cervical length for the prediction of spontaneous preterm birth in twin pregnancies: a systematic review and metaanalysis. Am J Obstet Gynecol 2010;203: 128.e1-12. [PubMed: 20576253]

55. Lim AC, Hegeman MA, Huis In 'T Veld MA, Opmeer BC, Bruinse HW, Mol BW. Cervical length measurement for the prediction of preterm birth in multiple pregnancies: a systematic review and bivariate meta-analysis. Ultrasound Obstet Gynecol 2011;38:10-7. [PubMed: 21465606]

56. Barros-Silva J, Pedrosa AC, Matias A. Sonographic measurement of cervical length as a predictor of preterm delivery: a systematic review. J Perinat Med 2014;42: 281-93. [PubMed: 24169309]

57. Conde-Agudelo A, Romero R. Prediction of preterm birth in twin gestations using biophysical and biochemical tests. Am J Obstet Gynecol 2014;211:583-95. [PubMed: 25072736]

58. Li Q, Reeves M, Owen J, Keith LG. Precocious cervical ripening as a screening target to predict spontaneous preterm delivery among asymptomatic singleton pregnancies: a systematic review. Am J Obstet Gynecol 2015;212: 145-56. [PubMed: 25017411]

59. Conde-Agudelo A, Romero R. Predictive accuracy of changes in transvaginal sonographic cervical length over time for preterm birth: a systematic review and metaanalysis. Am J Obstet Gynecol 2015;213:789-801. [PubMed: 26070703]

60. Pagani G, Stagnati V, Fichera A, Prefumo F. Cervical length at mid-gestation in screening for preterm birth in twin pregnancy. Ultrasound Obstet Gynecol 2016;48:56-60. [PubMed: 26250480]

61. Kindinger LM, Poon LC, Cacciatore S, et al. The effect of gestational age and cervical length measurements in the prediction of spontaneous preterm birth in twin pregnancies: an individual patient level meta-analysis. BJOG 2016;123: 877-84. [PubMed: 26333191]

62. Melamed N, Pittini A, Hiersch L, et al. Serial cervical length determination in twin pregnancies reveals 4 distinct patterns with prognostic significance for preterm birth. Am J Obstet Gynecol 2016;215:476.e1-11. [PubMed: 27207277]

63. Vandermolen BI, Hezelgrave NL, Smout EM, Abbott DS, Seed PT, Shennan AH. Quantitative fetal fibronectin and cervical length to predict preterm birth in asymptomatic women with previous cervical surgery. Am J Obstet Gynecol 2016;215:480.e1-10. [PubMed: 27267388] 
64. Melamed N, Pittini A, Hiersch L, et al. Do serial measurements of cervical length improve the prediction of preterm birth in asymptomatic women with twin gestations? Am J Obstet Gynecol 2016;215:616.e1-14. [PubMed: 27365003]

65. Moroz LA, Brock CO, Govindappagari S, Johnson DL, Leopold BH, Gyamfi-Bannerman C. Association between change in cervical length and spontaneous preterm birth in twin pregnancies. Am J Obstet Gynecol 2017;216:159.e1-7. [PubMed: 27729253]

66. Esplin MS, Elovitz MA, Iams JD, et al. Predictive accuracy of serial transvaginal cervical lengths and quantitative vaginal fetal fibronectin levels for spontaneous preterm birth among nulliparous women. JAMA 2017;317: 1047-56. [PubMed: 28291893]

67. Brock C, Moroz L, Gyamfi-Bannerman C. Is cervical length similarly predictive of preterm birth across races in twin gestation? Am J Obstet Gynecol 2017;216:S264-5.

68. Iams JD, Goldenberg RL, Mercer BM, et al. The Preterm Prediction Study: recurrence risk of spontaneous preterm birth. Am J Obstet Gynecol 1998;178:1035-40. [PubMed: 9609580]

69. Owen J, Yost N, Berghella V, et al. Midtrimester endovaginal sonography in women at high risk for spontaneous preterm birth. JAMA 2001;286:1340-8. [PubMed: 11560539]

70. Romero R, Nicolaides K, Conde-Agudelo A, et al. Vaginal progesterone in women with an asymptomatic sonographic short cervix in the midtrimester decreases preterm delivery and neonatal morbidity: a systematic review and metaanalysis of individual patient data. Am J Obstet Gynecol 2012;206:124.e1-19. [PubMed: 22284156]

71. Conde-Agudelo A, Romero R, Nicolaides K, et al. Vaginal progesterone vs. cervical cerclage for the prevention of preterm birth in women with a sonographic short cervix, previous preterm birth, and singleton gestation: a systematic review and indirect comparison metaanalysis. Am J Obstet Gynecol 2013;208:42.e1-18. [PubMed: 23157855]

72. Romero R, Yeo L, Miranda J, Hassan SS, Conde-Agudelo A, Chaiworapongsa T. A blueprint for the prevention of preterm birth: vaginal progesterone in women with a short cervix. J Perinat Med 2013;41:27-44. [PubMed: 23314512]

73. Romero R, Yeo L, Chaemsaithong P, Chaiworapongsa T, Hassan SS. Progesterone to prevent spontaneous preterm birth. Semin Fetal Neonatal Med 2014;19:15-26. [PubMed: 24315687]

74. International Federation of Gynecology and Obstetrics Working Group on Best Practice In Maternal-Fetal Medicine; International Federation of Gynecology and Obstetrics. Best practice in maternal-fetal medicine. Int J Gynaecol Obstet 2015;128:80-2. [PubMed: 25481030]

75. National Institute for Health and Care Excellence. Preterm labor and birth. NICE guideline 25. 2015 Available at: https://www.nice.org.uk/guidance/ng25/evidence/full-guideline2176838029. Accessed Jan. 30, 2018.

76. Conde-Agudelo A, Romero R. Vaginal progesterone to prevent preterm birth in pregnant women with a sonographic short cervix: clinical and public health implications. Am J Obstet Gynecol 2016;214:235-42. [PubMed: 26450404]

77. Romero R, Nicolaides KH, Conde-Agudelo A, et al. Vaginal progesterone decreases preterm birth $\$ 34$ weeks of gestation in women with a singleton pregnancy and a short cervix: an updated metaanalysis including data from the OPPTIMUM study. Ultrasound Obstet Gynecol 2016;48:308-17. [PubMed: 27444208]

78. O'Brien JM, Lewis DF. Prevention of preterm birth with vaginal progesterone or 17alphahydroxyprogesterone caproate: a critical examination of efficacy and safety. Am J Obstet Gynecol 2016;214:45-56. [PubMed: 26558340]

79. Vintzileos AM, Visser GH. Interventions for women with mid-trimester short cervix: which ones work? Ultrasound Obstet Gynecol 2017;49:295-300. [PubMed: 28266160]

80. Romero R, Conde-Agudelo A, Da Fonseca E, et al. Vaginal progesterone for preventing preterm birth and adverse perinatal outcomes in singleton gestations with a short cervix: a meta-analysis of individual patient data. Am J Obstet Gynecol 2018;218:161-80. [PubMed: 29157866]

81. Campbell S Prevention of spontaneous preterm birth: universal cervical length assessment and vaginal progesterone in women with a short cervix: time for action! Am J Obstet Gynecol 2018;218:151-8. [PubMed: 29422255] 
82. Berghella V, Rafael TJ, Szychowski JM, Rust OA, Owen J. Cerclage for short cervix on ultrasonography in women with singleton gestations and previous preterm birth: a metaanalysis. Obstet Gynecol 2011;117:663-71. [PubMed: 21446209]

83. Berghella V Cerclage decreases preterm birth: finally the level I evidence is here. Am J Obstet Gynecol 2011;205:89-90.

84. Society for Maternal-Fetal Medicine Publications Committee, with assistance of Vincenzo Berghella. Progesterone and preterm birth prevention: translating clinical trials data into clinical practice. Am J Obstet Gynecol 2012;206: 376-86. [PubMed: 22542113]

85. American College of Obstetricians and Gynecologists. Committee on Practice Bulletinse Obstetrics. Prediction and prevention of preterm birth. ACOG Practice bulletin no. 130. Obstet Gynecol 2012;120:964-73. [PubMed: 22996126]

86. American College of Obstetricians and Gynecologists. Cerclage for the management of cervical insufficiency. ACOG Practice bulletin no. 142. Obstet Gynecol 2014;123:372-9. [PubMed: 24451674]

87. Society for Maternal-Fetal Medicine (SMFM), McIntosh J, Feltovich H, Berghella V, Manuck T. The role of routine cervical length screening in selected high- and low-risk women for preterm birth prevention. Am J Obstet Gynecol 2016;215:B2-7.

88. Berghella V The power of meta-analysis to address an important clinical question in obstetrics. Am J Obstet Gynecol 2017;216:379.e1-4. [PubMed: 28143698]

89. Ionescu AC, Gheorghiu D, Pacu I, Davitoiu B, Dimitriu M, Haradja H. Randomized trial of cerclage and progesterone to prevent spontaneous preterm birth in high-risk women with a short cervix. J Perinat Med 2011;39(Suppl):Abstract 008.

90. Chandiramani M, Seed PT, Orsi NM, et al. Limited relationship between cervico-vaginal fluid cytokine profiles and cervical shortening in women at high risk of spontaneous preterm birth. PLoS One 2012;7:e52412. [PubMed: 23300664]

91. Norman JE, Marlow N, Messow C-M, et al. for the OPPTIMUM study group. Vaginal progesterone prophylaxis for preterm birth (the OPPTIMUM study): a multicentre, randomized, double-blind trial. Lancet 2016;387:2106-16. [PubMed: 26921136]

92. Song F, Altman DG, Glenny AM, Deeks JJ. Validity of indirect comparison for estimating efficacy of competing interventions: empirical evidence from published meta-analyses. BMJ 2003;326:472. [PubMed: 12609941]

93. Sutton A, Ades AE, Cooper N, Abrams K. Use of indirect and mixed treatment comparisons for technology assessment. Pharmacoeconomics 2008;26:753-67. [PubMed: 18767896]

94. Song F, Harvey I, Lilford R. Adjusted indirect comparison may be less biased than direct comparison for evaluating new pharmaceutical interventions. J Clin Epidemiol 2008;61:455-63. [PubMed: 18394538]

95. Wells GA, Sultan A, Chen L, Khan M, Coyle D. Indirect evidence: indirect treatment comparisons in meta-analysis. Ottawa, Canada: Canadian Agency for Drugs and Technologies in Health; 2009.

96. Edwards SJ, Clarke MJ, Wordsworth S, Borrill J. Indirect comparisons of treatments based on systematic reviews of randomized controlled trials. Int J Clin Pract 2009;63:841-54. [PubMed: 19490195]

97. Song F, Xiong T, Parekh-Bhurke S, et al. Inconsistency between direct and indirect comparisons of competing interventions: meta-epidemiological study. BMJ 2011;343:d4909. [PubMed: 21846695]

98. Abdelhamid AS, Loke YK, Parekh-Bhurke S, et al. Use of indirect comparison methods in systematic reviews: a survey of Cochrane review authors. Res Synth Methods 2012;3:71-9. [PubMed: 26062082]

99. Liberati A, Altman DG, Tetzlaff J, et al. The PRISMA statement for reporting systematic reviews and meta-analyses of studies that evaluate healthcare interventions: explanation and elaboration. BMJ 2009;339:b2700. [PubMed: 19622552]

100. Stewart LA, Clarke M, Rovers M, et al. Preferred reporting items for systematic review and metaanalyses of individual participant data: the PRISMA-IPD statement. JAMA 2015;313: 1657-65. [PubMed: 25919529]

101. Donegan S, Williamson P, Gamble C, Tudur-Smith C. Indirect comparisons: a review of reporting and methodological quality. PLoS One 2010;5:e11054. [PubMed: 21085712] 
102. Higgins J, Altman D, Sterne J. Chapter 8: Assessing risk of bias in included studies. Cochrane Handbook for Systematic Reviews of Interventions. Version 5.1.0 (updated March 2011). The Cochrane Collaboration; 2011.

103. Tierney JF, Vale C, Riley R, et al. Individual participant data (IPD) meta-analyses of randomized controlled trials: guidance on their use. PLoS Med 2015;12:e1001855. [PubMed: 26196287]

104. Higgins JP, Thompson SG, Deeks JJ, Altman DG. Measuring inconsistency in metaanalyses. BM 2003;327:557-60.

105. Altman DG. Confidence intervals for the number needed to treat. BMJ 1998;317: 1309-12. [PubMed: 9804726]

106. Bucher HC, Guyatt GH, Griffith LE, Walter SD. The results of direct and indirect treatment comparisons in meta-analysis of randomized controlled trials. J Clin Epidemiol 1997;50:683-91. [PubMed: 9250266]

107. Glenny AM, Altman DG, Song F, et al. Indirect comparisons of competing interventions. Health Technol Assess 2005;9:1-134, iii-iv.

108. Fonseca EB, Celik E, Parra M, Singh M, Nicolaides KH; Fetal Medicine Foundation Second Trimester Screening Group. Progesterone and the risk of preterm birth among women with a short cervix. N Engl J Med 2007;357:462-9. [PubMed: 17671254]

109. O'Brien JM, Adair CD, Lewis DF, et al. Progesterone vaginal gel for the reduction of recurrent preterm birth: primary results from a randomized, double-blind, placebo-controlled trial. Ultrasound Obstet Gynecol 2007;30: 687-96. [PubMed: 17899572]

110. Cetingoz E, Cam C, Sakallı M, Karateke A, Celik C, Sancak A. Progesterone effects on preterm birth in high-risk pregnancies: a randomized placebo-controlled trial. Arch Gynecol Obstet 2011;283:423-9. [PubMed: 20091317]

111. Hassan SS, Romero R, Vidyadhari D, et al. PREGNANT Trial. Vaginal progesterone reduces the rate of preterm birth in women with a sonographic short cervix: a multicenter, randomized, double-blind, placebo-controlled trial. Ultrasound Obstet Gynecol 2011;38: 18-31. [PubMed: 21472815]

112. Rust OA, Atlas RO, Reed J, van Gaalen J, Balducci J. Revisiting the short cervix detected by transvaginal ultrasound in the second trimester: why cerclage therapy may not help. Am J Obstet Gynecol 2001;185:1098-105. [PubMed: 11717641]

113. Althuisius SM, Dekker GA, Hummel P, Bekedam DJ, van Geijn HP. Final results of the Cervical Incompetence Prevention Randomized Cerclage Trial (CIPRACT): therapeutic cerclage with bed rest vs bed rest alone. Am J Obstet Gynecol 2001;185:1106-12. [PubMed: 11717642]

114. To MS, Alfirevic Z, Heath VC, et al. Cervical cerclage for prevention of preterm delivery in women with short cervix: randomised controlled trial. Lancet 2004;363:1849-53. [PubMed: 15183621]

115. Berghella V, Odibo AO, Tolosa JE. Cerclage for prevention of preterm birth in women with a short cervix found on transvaginal ultrasound examination: a randomized trial. Am J Obstet Gynecol 2004;191:1311-7. [PubMed: 15507959]

116. Owen J, Hankins G, Iams JD, et al. Multicenter randomized trial of cerclage for preterm birth prevention in high-risk women with shortened midtrimester cervical length. Am J Obstet Gynecol 2009;201:375.e1-8. [PubMed: 19788970]

117. van Os MA, van der Ven AJ, Kleinrouweler CE, et al. Preventing preterm birth with progesterone in women with a short cervical length from a low-risk population: a multicenter double-blind placebo-controlled randomized trial. Am J Perinatol 2015;32: 993-1000. [PubMed: 25738790]

118. Azargoon A, Ghorbani R, Aslebahar F. Vaginal progesterone on the prevention of preterm birth and neonatal complications in high risk women: a randomized placebo-controlled double-blind study. Int J Reprod Biomed (Yazd) 2016;14:309-16. [PubMed: 27326415]

119. Crowther CA, Ashwood P, McPhee AJ, et al. Vaginal progesterone pessaries for pregnant women with a previous preterm birth to prevent neonatal respiratory distress syndrome (the PROGRESS study): a multicenter, randomized, placebo-controlled trial. PLoS Med 2017;14:e1002390. [PubMed: 28949973] 
120. Otsuki K, Nakai A, Matsuda Y, et al. Randomized trial of ultrasound-indicated cerclage in singleton women without lower genital tract inflammation. J Obstet Gynaecol Res 2016;42: 14857. [PubMed: 26633738]

121. Berghella V, Figueroa D, Szychowski JM, et al. 17-Alpha-hydroxyprogesterone caproate for the prevention of preterm birth in women with prior preterm birth and a short cervical length. Am J Obstet Gynecol 2010;202:351.e1-6. [PubMed: 20350641]

122. Jo B Statistical power in randomized intervention studies with noncompliance. Psychol Methods 2002;7:178-93. [PubMed: 12090409]

123. Alfirevic Z, Stampalija T, Medley N. Cervical stitch (cerclage) for preventing preterm birth in singleton pregnancy. Cochrane Database Syst Rev 2017;6:CD008991. [PubMed: 28586127]

124. Grobman WA, Thom EA, Spong CY, et al. 17 Alpha-hydroxyprogesterone caproate to prevent prematurity in nulliparas with cervical length less than $30 \mathrm{~mm}$. Am J Obstet Gynecol 2012;207:390.e1-8. [PubMed: 23010094]

125. Winer N, Bretelle F, Senat MV, et al. 17 Alpha-hydroxyprogesterone caproate does not prolong pregnancy or reduce the rate of preterm birth in women at high risk for preterm delivery and a short cervix: a randomized controlled trial. Am J Obstet Gynecol 2015;212:485.e1-10. [PubMed: 25448515]

126. Roeckner JT, Sanchez-Ramos L. The comparative efficacy of cervical pessary, cerclage, vaginal and parenteral progesterone for the prevention of preterm birth in women with a sonographic short cervix and a singleton gestation: a systematic review and network meta-analysis. Am J Obstet Gynecol 2017;216: S382.

127. Dodd JM, Jones L, Flenady V, Cincotta R, Crowther CA. Prenatal administration of progesterone for preventing preterm birth in women considered to be at risk of preterm birth. Cochrane Database Syst Rev 2013;7: CD004947.

128. Dodd JM, Grivell RM, O’Brien CM, Dowswell T, Deussen AR. Prenatal administration of progestogens for preventing spontaneous preterm birth in women with a multiple pregnancy. Cochrane Database Syst Rev 2017;10:CD012024. [PubMed: 29086920]

129. Romero R, Conde-Agudelo A, El-Refaie W, et al. Vaginal progesterone decreases preterm birth and neonatal morbidity and mortality in women with a twin gestation and a short cervix: an updated meta-analysis of individual patient data. Ultrasound Obstet Gynecol 2017;49: 303-14. [PubMed: 28067007]

130. O’Brien JM, Steichen JJ, Phillips JA, Creasy GW. Two year infant outcomes for children exposed to supplemental intravaginal progesterone gel in utero: secondary analysis of a multicenter, randomized, double-blind, placebo-controlled trial. Am J Obstet Gynecol 2012;206:S223.

131. McNamara HC, Wood R, Chalmers J, et al. STOPPIT Baby Follow-up Study: the effect of prophylactic progesterone in twin pregnancy on childhood outcome. PLoS One 2015;10: e0122341. [PubMed: 25881289]

132. Vedel C, Larsen H, Holmskov A, et al. Long-term effects of prenatal progesterone exposure: neurophysiological development and hospital admissions in twins up to 8 years of age. Ultrasound Obstet Gynecol 2016;48:382-9. [PubMed: 27106105]

133. van 't Hooft J, Cuijpers C, Schneeberger C, et al. Preventing preterm birth with progesterone in women with short cervical length, outcomes in children at 24 months of age. Am J Obstet Gynecol 2017;216:S492.

134. Murray SR, Stock SJ, Norman JE. Long-term childhood outcomes after interventions for prevention and management of preterm birth. Semin Perinatol 2017;41:519-27. [PubMed: 29191292]

135. Cahill AG, Odibo AO, Caughey AB, et al. Universal cervical length screening and treatment with vaginal progesterone to prevent preterm birth: a decision and economic analysis. Am J Obstet Gynecol 2010;202:548.e1-8. [PubMed: 20079888]

136. Werner EF, Han CS, Pettker CM, et al. Universal cervical-length screening to prevent preterm birth: a cost-effectiveness analysis. Ultrasound Obstet Gynecol 2011;38:32-7. [PubMed: 21157771] 
137. Werner EF, Hamel MS, Orzechowski K, Berghella V, Thung SF. Cost-effectiveness of transvaginal ultrasound cervical length screening in singletons without a prior preterm birth: an update. Am J Obstet Gynecol 2015;213:554.e1-6. [PubMed: 26071914]

138. Einerson BD, Grobman WA, Miller ES. Cost-effectiveness of risk-based screening for cervical length to prevent preterm birth. Am J Obstet Gynecol 2016;215:100.e1-7. [PubMed: 26880732]

139. Crosby DA, Miletin J, Semberova J, Daly S. Is routine transvaginal cervical length measurement cost-effective in a population where the risk of spontaneous preterm birth is low? Acta Obstet Gynecol Scand 2016;95:1391-5. [PubMed: 27623283]

140. Pizzi LT, Seligman NS, Baxter JK, Jutkowitz E, Berghella V. Cost and cost effectiveness of vaginal progesterone gel in reducing preterm birth: an economic analysis of the PREGNANT trial. Pharmacoeconomics 2014;32:467-78. [PubMed: 24715602]

141. Jain S, Kilgore M, Edwards RK, Owen J. Revisiting the cost-effectiveness of universal cervical length screening: importance of progesterone efficacy. Am J Obstet Gynecol 2016;215:101.e1-7. [PubMed: 26821336]

142. Page J, Emerson J, Cahill A, et al. The impact of cervical length on the costeffectiveness of vaginal progesterone as a preterm birth intervention. ACOG Practice bulletin no. 126. Am J Obstet Gynecol 2013;208:S66.

143. Brown S, Mozurkewich E. Cost analysis of universal cervical length screening and progesterone therapy in remote populations. ACOG Practice bulletin no. 397. Am J Obstet Gynecol 2014;210:S201.

144. Fonseca EB, Nishikawa AM, Paladini L, Clark OA. Cervical assessment with progesterone in the prevention of preterm birth: a strategy based on cost-effectiveness. Value Health 2014;17:A510.

145. Son M, Grobman WA, Ayala NK, Miller ES. A universal mid-trimester transvaginal cervical length screening program and its associated reduced preterm birth rate. Am J Obstet Gynecol 2016;214:365.e1-5. [PubMed: 26928150]

146. Temming LA, Durst JK, Tuuli MG, et al. Universal cervical length screening: implementation and outcomes. Am J Obstet Gynecol 2016;214:523.e1-8. [PubMed: 26874299]

147. Green PM, Argyelan A, Mutual F, Nynas J, Williams J, Keeton K. Implementation of universal cervical length screening is associated with a reduction in the rate of spontaneous preterm delivery in a low-risk cohort. Am J Obstet Gynecol 2017;216:S10.

148. Newnham JP, White SW, Meharry S, et al. Reducing preterm birth by a statewide multifaceted program: an implementation study. Am J Obstet Gynecol 2017;216:434-42. [PubMed: 27890647]

149. Miller E, Grobman WA. Cost-effectiveness of cervical length screening to prevent recurrent preterm birth. Am J Obstet Gynecol 2011;204:S191.

150. Eke A, Buras A, Drnec S, Woo J. Vaginal progesterone vs cervical cerclage for the prevention of preterm births in women with a sonographically short cervix - a cost effectiveness and decision analysis. Am J Obstet Gynecol 2015;212:S367-8.

151. Gray L, Seligman N, Ozcan T, Berghella V. Transvaginal cervical length ultrasound: a cost analysis of screening and treatment strategies in high-risk women. Am J Obstet Gynecol 2015;212:S253.

152. Society for Maternal-Fetal Medicine (SMFM) Publications Committee. The choice of progestogen for the prevention of preterm birth in women with singleton pregnancy and prior preterm birth. Am J Obstet Gynecol 2017;216:B11-3. [PubMed: 28126367] 


\section{AJOG at a Glance}

\section{What is the purpose of this study?}

To compare the efficacy of vaginal progesterone and cerclage in preventing preterm birth and adverse perinatal outcomes in women with a singleton gestation, previous spontaneous preterm birth, and a midtrimester sonographic short cervix.

\section{Key Findings}

Both vaginal progesterone and cerclage were associated with a significant reduction in the risk of preterm birth $<35$ and $<32$ weeks of gestation and composite perinatal morbidity/mortality compared to placebo/no cerclage. Adjusted indirect comparison meta-analyses showed no statistically significant differences between vaginal progesterone and cerclage in preventing preterm birth $<35$ and $<32$ weeks of gestation and composite perinatal morbidity/mortality.

\section{What does this add to what is known?}

This updated meta-analysis reaffirms that vaginal progesterone and cerclage are equally effective in preventing preterm birth and improving perinatal outcomes in women with a singleton gestation, previous spontaneous preterm birth, and a sonographic short cervix. These results should prompt revisiting of the guidelines of professional organizations in which only cervical cerclage is recommended to patients with these characteristics. Vaginal progesterone is a medical alternative that does not require anesthesia and surgery. 


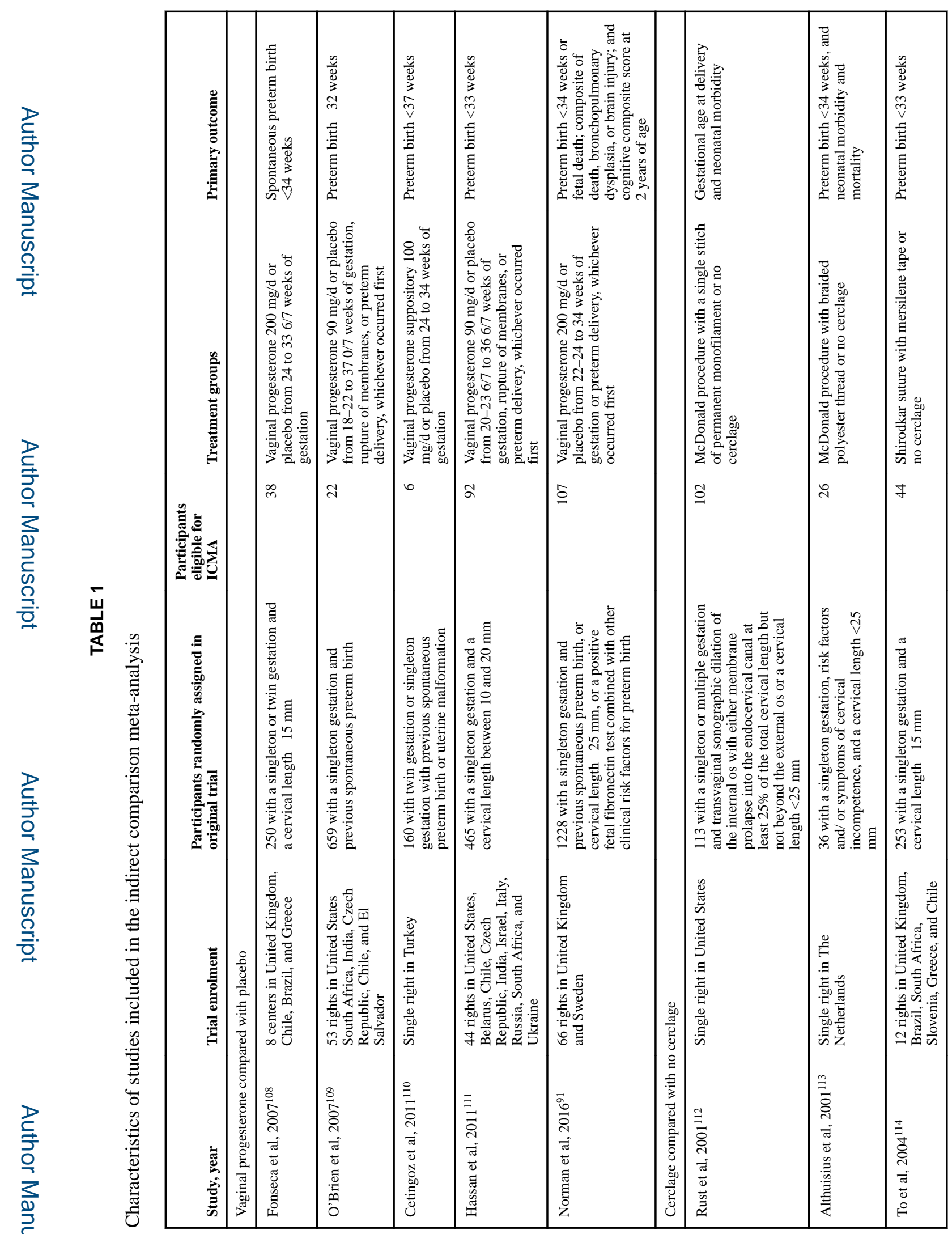

Am J Obstet Gynecol. Author manuscript; available in PMC 2019 July 01. 


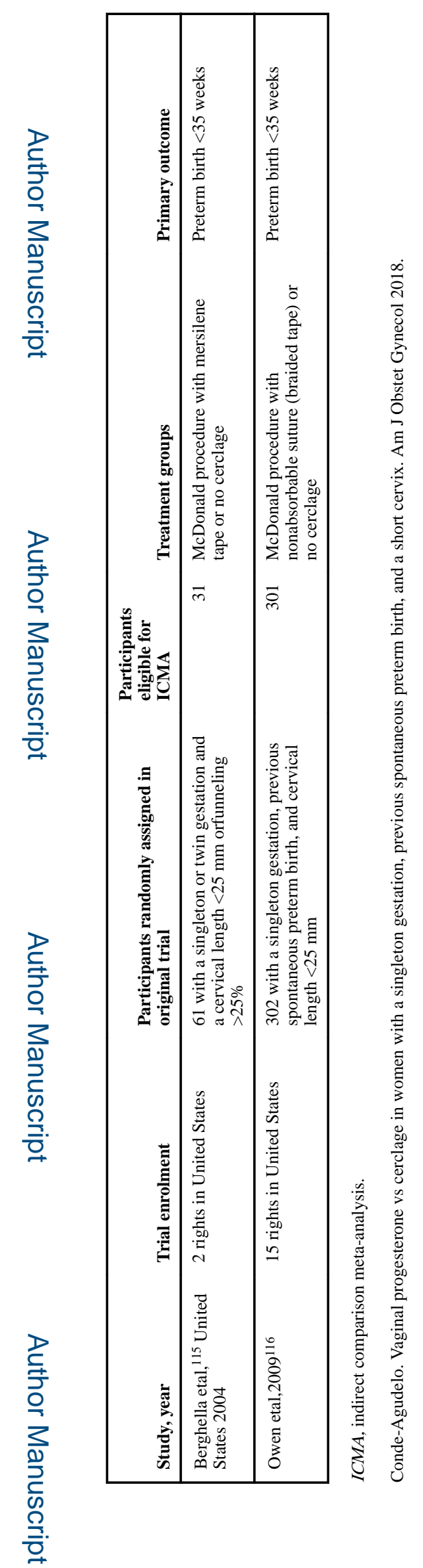

Am J Obstet Gynecol. Author manuscript; available in PMC 2019 July 01. 


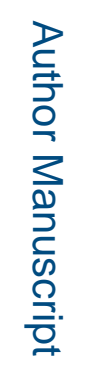

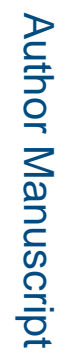

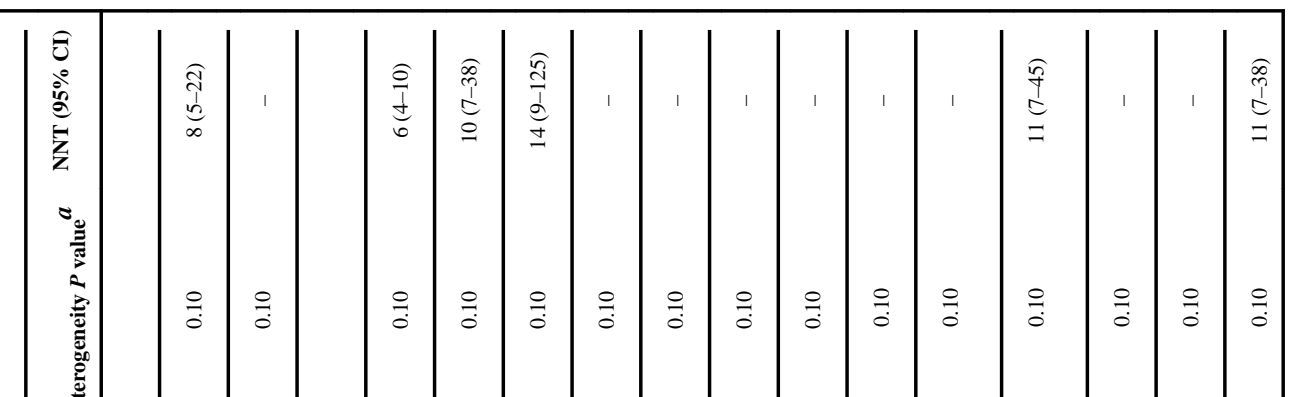

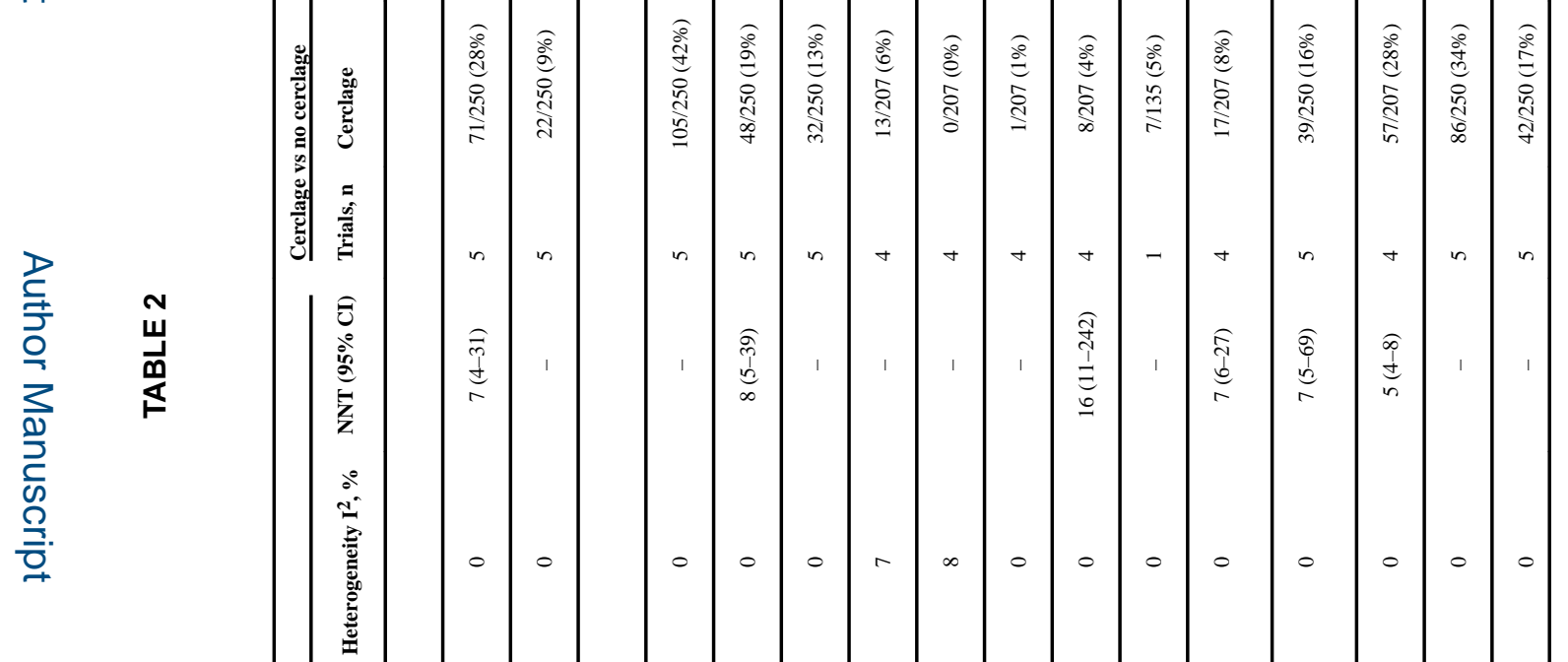

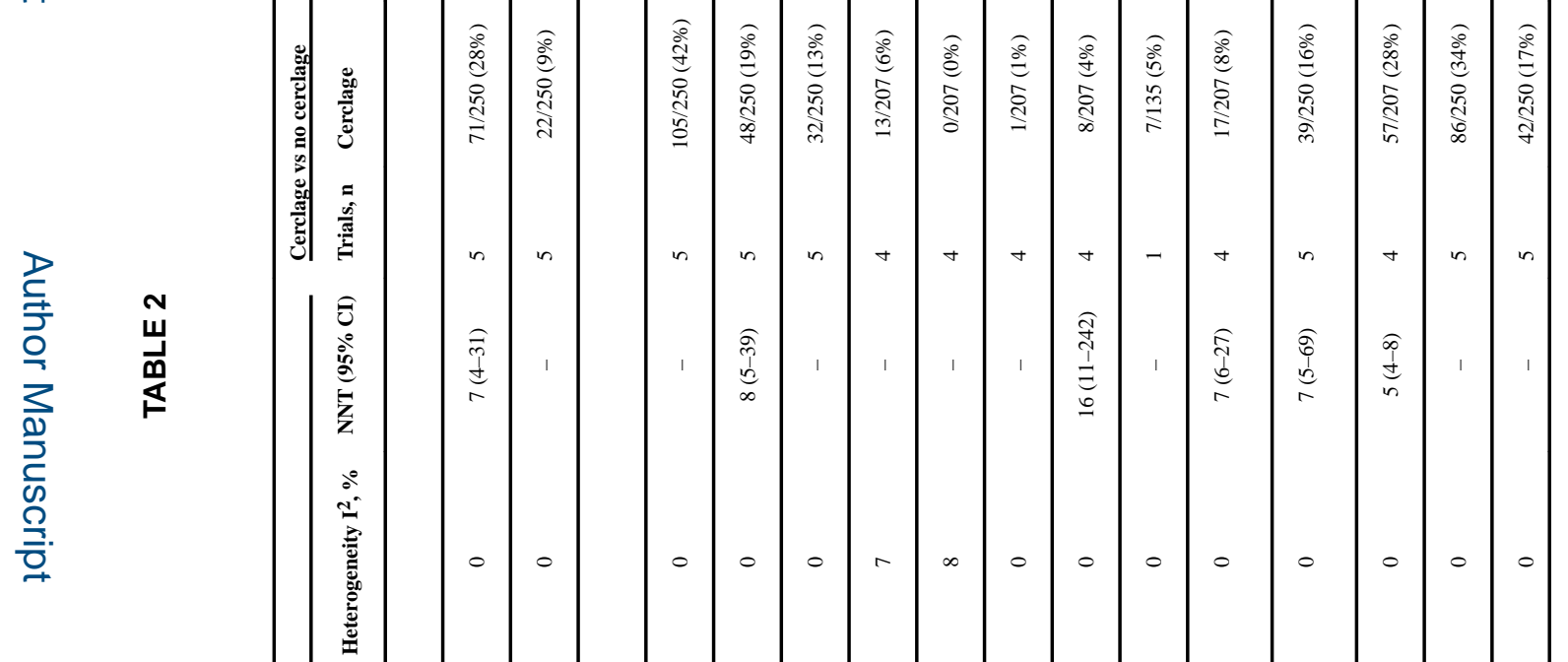

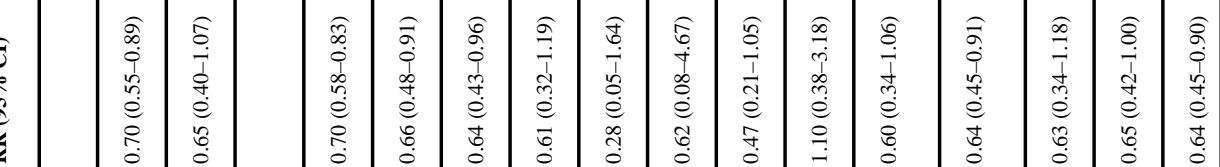

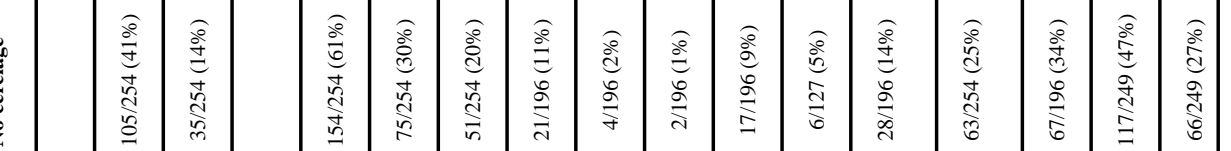

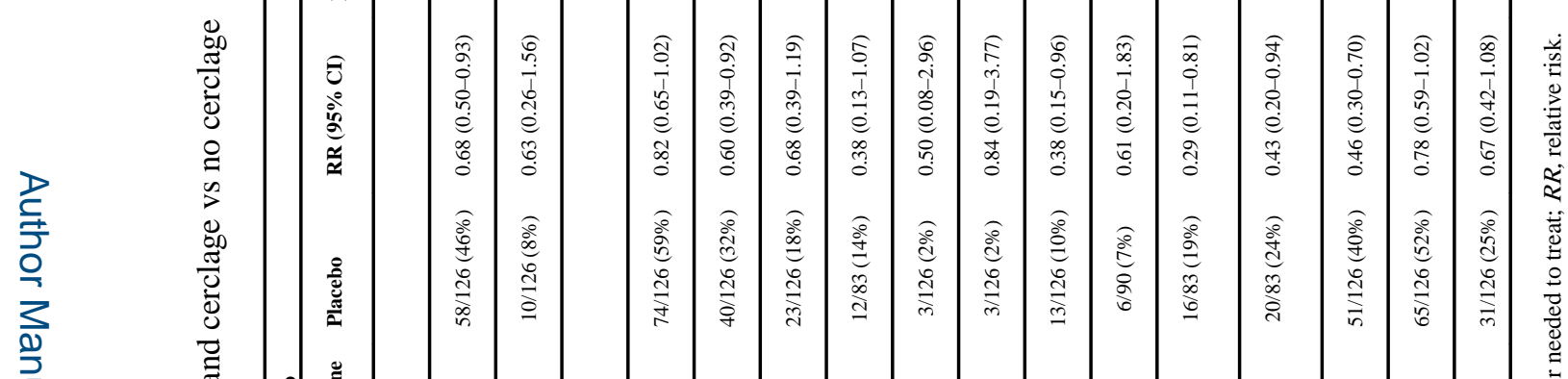

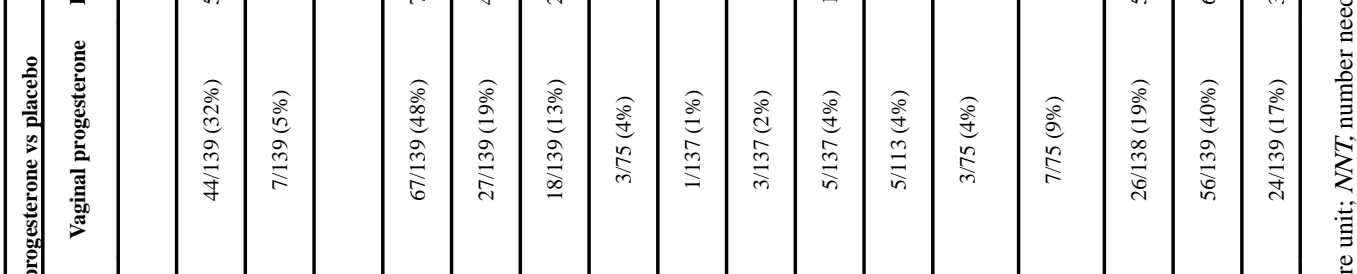

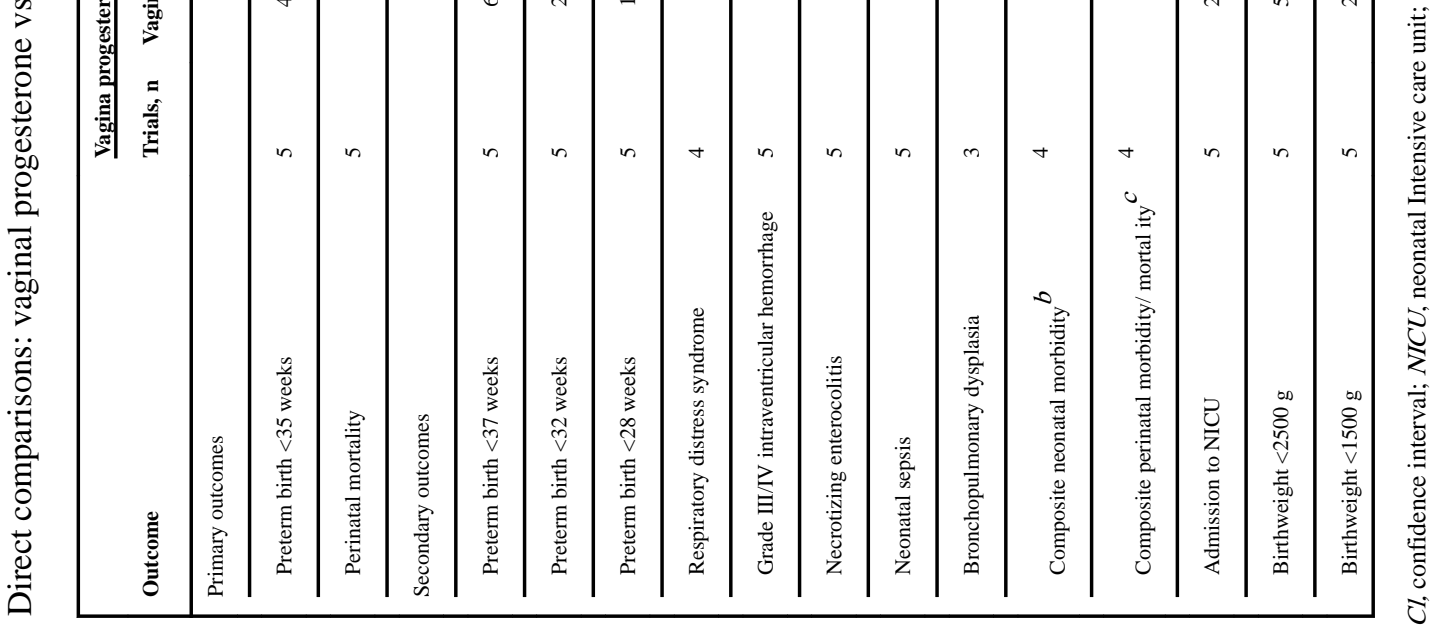




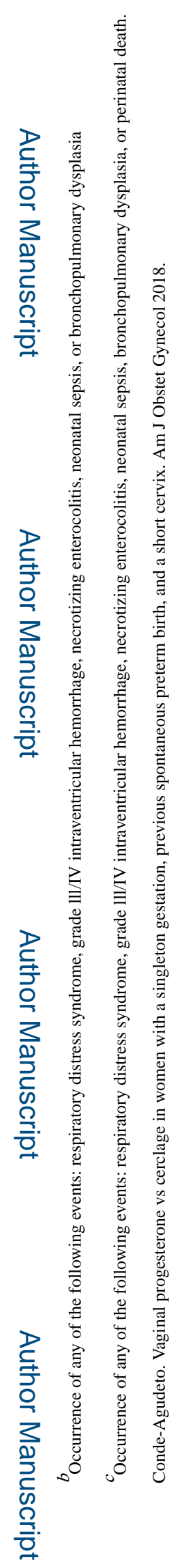




\section{TABLE 3}

Indirect comparison: vaginal progesterone vs cerclage

\begin{tabular}{|lll|}
\hline & \multicolumn{2}{l}{ Vaginal progesterone vs cerclage } \\
\cline { 2 - 3 } Outcome & RR (95\% CI) $)^{\boldsymbol{a}}$ & $\boldsymbol{P}^{\text {P value }} \boldsymbol{b}$ \\
\hline Primary outcomes & \\
\hline Preterm birth $<35$ weeks & $0.97(0.66-1.44)$ & .93 \\
\hline Perinatal mortality & $0.97(0.35-2.69)$ & .96 \\
\hline Secondary outcomes & & \\
\hline Preterm birth $<37$ weeks & $1.17(0.88-1.56)$ & .61 \\
\hline Preterm birth $<32$ weeks & $0.91(0.53-1.55)$ & .79 \\
\hline Preterm birth <28 weeks & $1.06(0.53-2.11)$ & .89 \\
\hline Respiratory distress syndrome & $0.62(0.18-2.16)$ & .84 \\
\hline Grade III/IV intraventricular hemorrhage & $1.79(0.15-22.00)$ & .76 \\
\hline Necrotizing enterocolitis & $1.36(0.11-16.89)$ & .84 \\
\hline Neonatal sepsis & $0.81(0.24-2.76)$ & .76 \\
\hline Bronchopulmonary dysplasia & $0.56(0.12-2.57)$ & .49 \\
\hline Composite neonatal morbidity ${ }^{c}$ & $0.48(0.15-1.53)$ & .75 \\
\hline Composite perinatal morbidity/mortality ${ }^{d}$ & $0.67(0.29-1.57)$ & .86 \\
\hline Admission to NICU & $0.73(0.34-1.55)$ & .38 \\
\hline Birthweight $<2500 \mathrm{~g}$ & $1.20(0.72-2.00)$ & .56 \\
\hline Birthweight $<1500 \mathrm{~g}$ & $1.05(0.58-1.88)$ & .90 \\
\hline
\end{tabular}

$C I$, confidence interval; $N I C U$, neonatal intensive care unit; $R R$ relative risk.

${ }^{a} \mathrm{RR}<1$ favors vaginal progesterone and $\mathrm{RR}>1$ favors cerclage

${ }^{b}$ For the test of association

${ }^{c}$ Occurrence of any of the following events: respiratory distress syndrome, grade III/IV intraventricular hemorrhage, necrotizing enterocolitis, neonatal sepsis, or bronchopulmonary dysplasia

${ }^{d}$ Occurrence of any of the following events: respiratory distress syndrome, grade III/IV intraventricular hemorrhage, necrotizing enterocolitis, neonatal sepsis, bronchopulmonary dysplasia, or perinatal death.

Conde-Agudelo. Vaginal progesterone vs cerclage in women with a singleton gestation, previous spontaneous preterm birth, and a short cervix. Am J Obstet Gynecol 2018. 


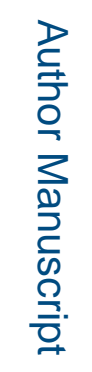

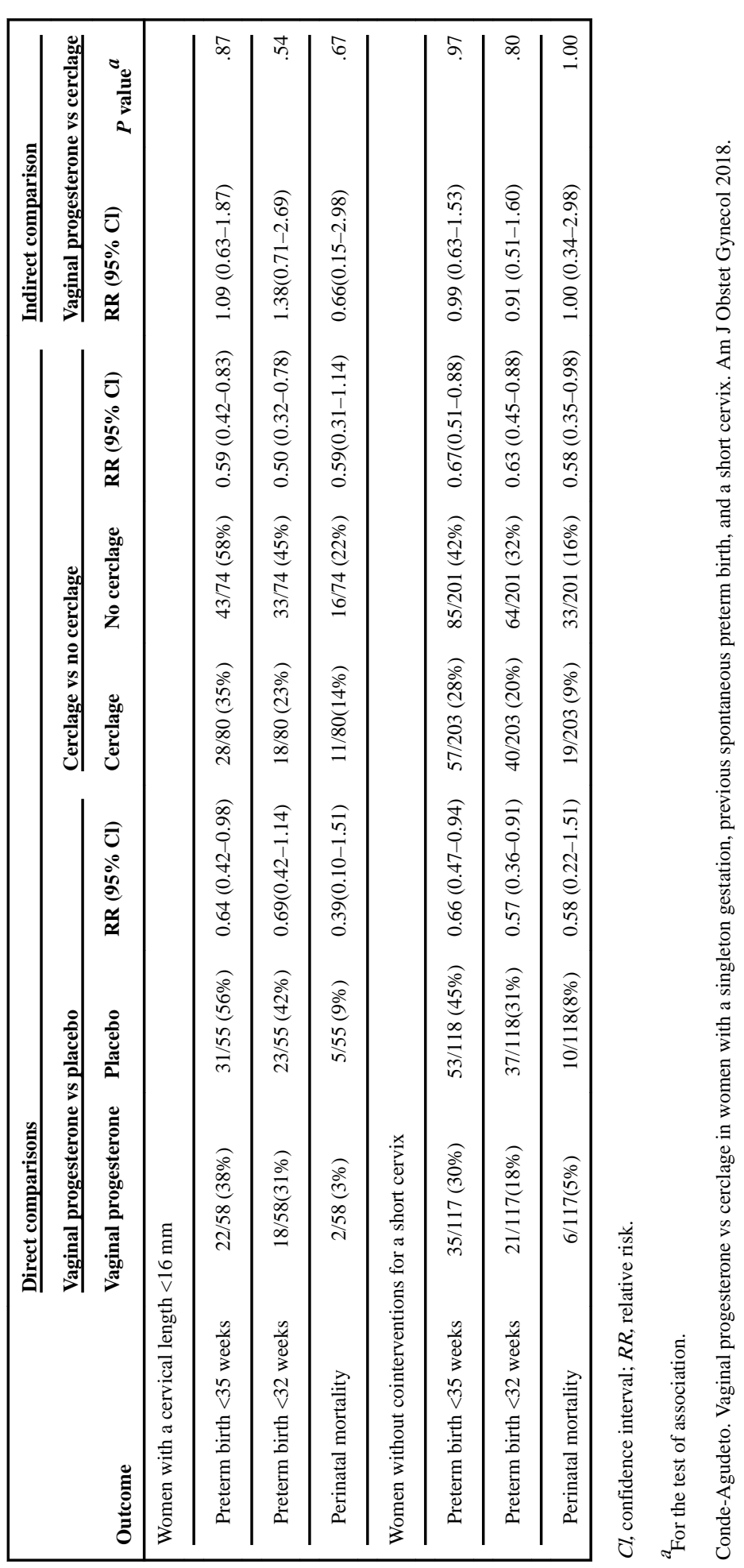

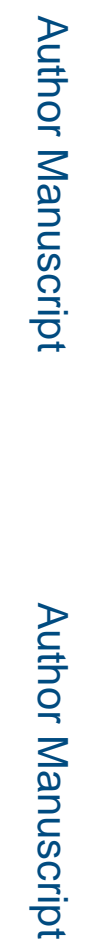

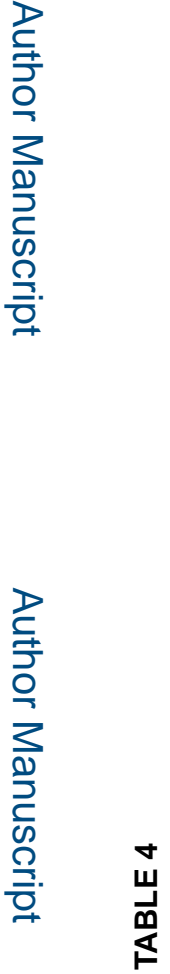

